Annales Geophysicae (2004) 22: 387-404 (C) European Geosciences Union 2004

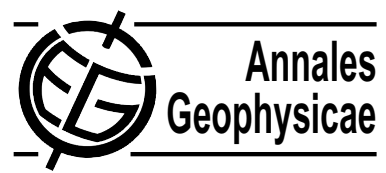

\title{
Meteor radar observations of atmospheric waves in the equatorial mesosphere/lower thermosphere over Ascension Island
}

\author{
D. Pancheva ${ }^{1}$, N. J. Mitchell ${ }^{1}$, and P. T. Younger ${ }^{1}$ \\ ${ }^{1}$ Department of Electronic \& Electrical Engineering, University of Bath, Bath, BA2 7AY, UK \\ Received: 18 November 2002 - Revised: 9 June 2003 - Accepted: 18 June 2003 - Published: 1 January 2004
}

\begin{abstract}
Some preliminary results about the planetary wave characteristics observed during the first seven months (October 2001-April 2002) of observations over Ascension Island $\left(7.9^{\circ} \mathrm{S}, 14.4^{\circ} \mathrm{W}\right)$ are reported in this study. The zonal wind is dominated by the 3-7-day waves, while the meridional component - by the quasi-2-day wave. Two wave events in the zonal wind are studied in detail: a 3-4-day wave observed in the end of October/November and the 3-6day wave in January/February. The moderate 3- and 3.2-day waves are interpreted as an ultra-fast Kelvin wave, while for the strong 4-day wave we are not able to make a firm decision. The 6-day wave is interpreted as a Doppler-shifted 5-day normal mode, due to its very large vertical wavelength $(79 \mathrm{~km})$. The quasi-2-day wave seems to be present almost continuously in the meridional wind, but the strongest bursts are observed mainly in December and January. The observed period range is large, from 34 to $68 \mathrm{~h}$, with some clustering around 43-44 and $50 \mathrm{~h}$. The estimated vertical wavelengths indicate shorter lengths during the equinoxes, in the range of $25-30 \mathrm{~km}$, and longer ones, $\sim 40-50 \mathrm{~km}$, in January/February, when the 48-h wave is strongest.
\end{abstract}

Key words. Meteorology and atmospheric dynamics (middle atmosphere dynamics, waves and tides)

\section{Introduction}

It is well known that the circulation of the equatorial middle atmosphere, unlike that at extra-tropical latitudes, is not dominated by annual oscillation (Andrews et al., 1987). At heights below $35 \mathrm{~km}$ the winds are dominated by a quasibiennial oscillation (QBO), while above $35 \mathrm{~km}$ - by a semiannual oscillation (SAO) (Ebdon, 1960; Reed, 1962). It is found by rocket and satellite measurements that the SAO has maximum amplitudes near the stratopause $(\sim 50 \mathrm{~km})$ and mesopause $(\sim 85 \mathrm{~km})$, with a minimum near $65 \mathrm{~km}$, and the stratospheric SAO (SSAO) and mesospheric SAO (MSAO)

Correspondence to: D. Pancheva (eesdvpbath.ac.uk) are in anti-phase (Hirota, 1978; Hamilton, 1982; Garcia et al., 1997). The QBO and SAO are centred at or near the equator, and their cycles start first at upper levels and then descend steadily with time. Descending wind regimes are usually a characteristic of a circulation driven primarily by waves propagating from below. So, upward coupling of energy and momentum by waves generated in regions of intense tropospheric convection is expected to be important for determining the state of the equatorial middle atmosphere. There is some evidence that waves, such as Kelvin and Rossbygravity waves, play a crucial role in driving the QBO in the lower stratosphere (Lindzen and Holton, 1968) and the SSAO (Dunkerton, 1979). Recent studies, however, have suggested that additional momentum deposition by gravity waves is necessary to quantitatively explain the behaviour of the QBO (Dunkerton, 1997). It has been suggested that momentum deposition associated with breaking or dissipating Kelvin waves, atmospheric tides and gravity waves are also important for the MSAO (Hirota, 1978; Dunkerton, 1982), despite the fact that the precise mechanisms are poorly understood. The role of the equatorial Kelvin waves in producing the zonal mean eastward flow associated with the lower stratospheric QBO, SSAO and MSAO, however, has been debated recently.

Some numerical simulations (for example, Hitchman and Leovy, 1988) indicated that Kelvin waves were apparently too weak to fully drive the eastward phase of the SSAO. Several mechanisms are likely to be responsible for the SSAO and MSAO. This debate has strongly stimulated the observations of the equatorial atmospheric waves and especially Kelvin waves.

Recently, a few studies using both satellite and groundbased measurements revealed the characteristics of Kelvin waves, especially in the mesosphere/lower thermosphere (MLT) region (Lieberman and Riggin, 1997; Riggin et al., 1997; Smith, 1999; Kovalam et al., 1999; Yoshida et al., 1999; Sridharan et al., 2002). On the basis of the HRDI data obtained by the UARS mission, Lieberman and Riggin (1997) concluded that the 3-day Kelvin waves are an im- 
portant source of eastward momentum in the lower thermosphere $\sim 100 \mathrm{~km}$, but also that they are likely to be ineffective in the MSAO near $\sim 85 \mathrm{~km}$. Smith (1999), also using HRDI data, presented evidence for a quasi-stationary Kelvin wave of zonal wave number 1 that is forced in situ in the upper mesosphere and propagates upward from there. She found that the momentum transport by this Kelvin wave is small and does not make a significant contribution to the MSAO. Kovalam et al. (1999) and Sridharan et al. (2002) using the medium frequency (MF) radar data, determined that the role of the Kelvin waves in the mesospheric momentum budget is small. The results of Yoshida et al. (1999) based on the meteor radar and radiosonde observations in Indonesia suggested a possible interaction between the Kelvin waves observed in the MLT region and the MSAO, although an exact mechanism is uncertain. They also investigated the Kelvin waves in the stratosphere, but their semiannual periodicity was not detected there.

The quasi-2-day wave that can attain large amplitudes particularly in the meridional wind component of the equatorial MLT region is another strong feature that could be responsible for the momentum budget of the middle atmosphere. This oscillation has been extensively reported in radar neutral wind observations (Muller, 1972; Salby and Roper, 1980; Craig et al., 1980; Plumb et al., 1987; Tsuda et al., 1988; Raghava Reddi et al., 1988; Harris and Vincent, 1993; Palo and Avery, 1995; Thayaparan et al., 1997a; Gurubaran et al., 2001), in rocket-sonde winds in the upper stratosphere (Coy, 1979) and in the satellite coverage of the middle atmosphere (Rodgers and Prata, 1981; Burks and Leovy, 1986, Wu et al., 1993, Ward et al., 1996; Lieberman, 1999). The longitudinally-spaced radar comparisons suggest that the 2day wave is westward propagating with zonal wave numbers ranging between 2 and 5 (Muller and Nelson, 1978; Meek et al., 1996; Thayaparan et al., 1997b), while satellite analyses indicate westward propagation mainly with zonal wave numbers between 2 and 4 (Lieberman, 1999).

The 2-day wave is a global-scale oscillation with amplitude maximum between 80 and $100 \mathrm{~km}$ in July-August in the Northern Hemisphere and January-February in the Southern Hemisphere. Amplitudes are larger in the Southern Hemisphere, being up to a factor of two more than those found in the Northern Hemisphere. The observations in the equatorial and low latitudes (Harris and Vincent, 1993; Palo and Avery, 1995; Gurubaran et al., 2001) indicate that the activity is stronger in both summer and winter in the meridional component and is found to be much stronger in January-February than in June-July. In the Southern Hemisphere the period is close to $48 \mathrm{~h}$, while in the Northern Hemisphere it is ranging between 43 and $53 \mathrm{~h}$. The vertical wavelength calculated from the rate of change of phase with height is found to range from 20 to more than $150 \mathrm{~km}$.

Two mechanisms have been proposed as a cause for the presence of the 2-day wave in the middle atmosphere. One is based on the normal mode theory (Salby, 1981) that interprets the wave as a manifestation of the $(3,0)$ Rossbygravity mode. Hagan et al. (1993) have extended the re- sults of Salby (1981) by changing the mean wind field to include the summer mesospheric jet. They found that the stratospheric and mesospheric zonal mean winds strongly affect the salient features of the 2-day wave observed in the MLT region. Plumb (1983) and Pfister (1985) gave an alternative explanation of the 2-day wave, suggesting that the wave is excited in a baroclinically unstable summer mesospheric jet. It is known that both mechanisms cannot explain some wave features, such as hemispheric differences in the amplitude and the wave period. Therefore, more observations are needed to clarify certain key questions related to the generating mechanisms, the effects of mean wind on the wave features and the role of the 2-day wave in the momentum budget of the middle atmosphere.

Understanding of dynamics of the equatorial MLT region has improved recently because of the installation of several MF and meteor radars in India, Indonesia, Christmas Island (Republic of Kiribati) and Peru. They cover mainly a longitudinal range east of $78^{\circ} \mathrm{E}$ and west of $80^{\circ} \mathrm{W}$, so a range with more than $150^{\circ}$ continuous length is left without any measurements. This gap was partly filled with the installation of the meteor radar at Ascension Island $\left(7.9^{\circ} \mathrm{S}, 14.4^{\circ} \mathrm{W}\right)$ in 2001. The description of the radar, and distribution and processing of the raw data, as well as the first results for the mean wind and tides observed above Ascension Island, are presented in Mitchell et al. (2002). In this study we report some preliminary results about the planetary wave characteristics observed during the first seven months of observations between October 2001 and the end of April 2002.

\section{Data analysis}

The meteor radar at Ascension Island operates at frequency near 43.5 MHz. It measures wind over an altitude range of $80-100 \mathrm{~km}$, with velocities sampled at $\sim 3 \mathrm{~km}$ height resolution and a maximum data rate around $90 \mathrm{~km}$. The mean hourly horizontal wind velocities are used in this analysis. To reveal the underlying winds and tides, we used a best-fit procedure to extract these waves from the time series. Data were analysed using a simple linear least-squares fit which included a mean wind, and 24-, 12- and 8-h harmonic components. The data points were weighted in the fitting process according to the number of individual measurements composing each hourly mean. The harmonic components were determined in segments of 24- $h$ duration. The mean wind and tidal characteristics are obtained only when the segment consists of more than 16 measurements. Then the segment was incremented through the time series in steps of $1 \mathrm{~h}$ and the analysis repeated, yielding hourly-spaced values for the mean wind, and 24-, 12- and 8-h tidal amplitudes and phases. Each height is treated separately in this analysis. To estimate the confidence levels we assumed that the residual fitting error is described by a Gaussian-white noise. The Student Ttest was then used to estimate the confidence levels.

The waves studied in this paper were found to be highly dynamic with amplitude and phase changes over relatively 


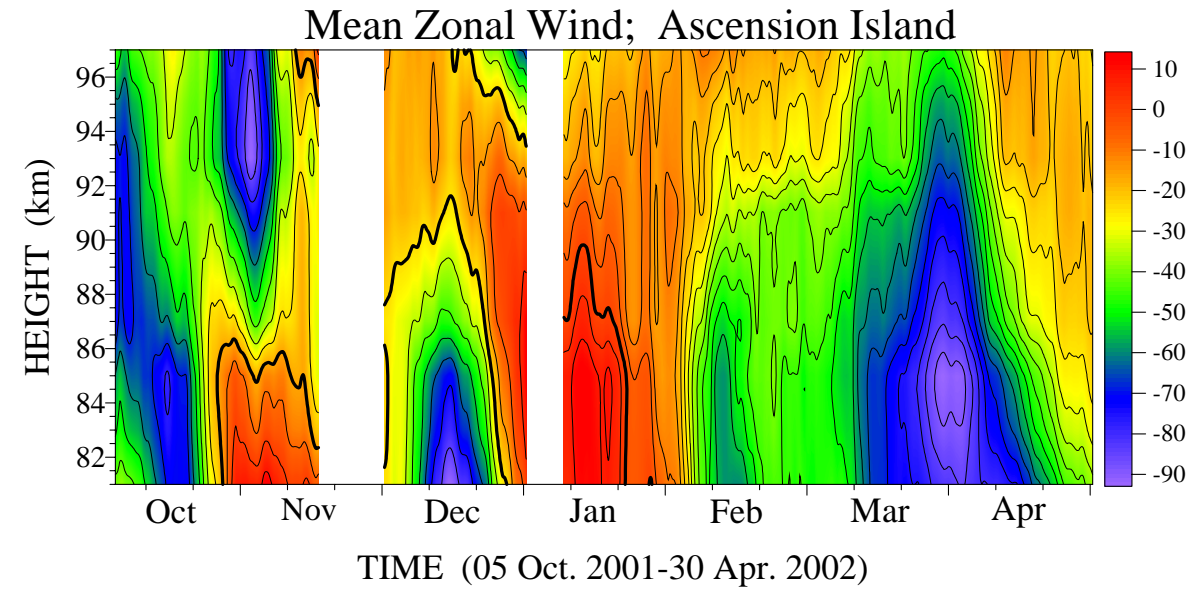

Fig. 1. Time-height cross section of the smoothed zonal wind (by 10-day running means) observed over Ascension Island between October 2001 and April 2002. Solid line indicates zero velocity. The white regions indicate missing data. short time scales. The wavelet transform was used to investigate the changing composition of the planetary-wave field. This approach is becoming a favoured tool for analysing time series in which the assumption of stationarity does not hold. Decomposing the time series into time-frequency space, the wavelet transform is able to determine both the constituent frequencies and how those frequencies vary in time, producing a two-dimensional time-frequency image (Torrence and Compo, 1998). The analysis presented here used the continuous Morlet wavelet, which consists of a plane wave modulated by a Gaussian envelope. The Morlet wavelet was selected because of its simplicity and resemblance to the modulated planetary-wave "packets", which are frequently observed in the ionosphere and MLT region variability (Pancheva and Mukhtarov, 2000). Additional spectral information was gained by applying the high-resolution correloperiodogram analysis (Kopecky and Kuklin, 1971).

A weakness of the wavelet transform used here is that it requires regularly spaced data points in the time series in consideration, i.e. there should be no gaps in the data. In the present work, small data gaps of $2-4 \mathrm{~h}$ in duration were filled by an interpolation based on data on either side of the gap using a least-squares fit of a second-degree polynomial with exponentially decreasing weights away from the gap in the data. Larger gaps of between 4 and $8 \mathrm{~h}$ in duration were filled by applying a daily tidal fit, and the gaps were then filled with the fitted values, plus a random error distributed uniformly in the range of \pm 1 standard deviation. If the length of the gap was longer than $8 \mathrm{~h}$ (there are only a few cases), the following procedure was used, which is appropriate for cases where the frequency of the dominant signals in a time series is known in advance (as in our case with 12- and 24-h tides). First, the data neighbouring the gap interval, with a length at least two times longer than the gap, were examined to determine the mean amplitudes and phases of the strongest periodic components (i.e. the tides in our case). The gap was then filled with data derived from these results, with the constraint that the variance of the data used to fill the gap must have the same variance as that of the neighbouring intervals.
A complex demodulation method is usually used for effective investigation of one frequency range at a time (Bloomfield, 1976). We applied this method for studying the quasi2-day wave, whose period changes mainly between 40 and $60 \mathrm{~h}$. This technique allows for the amplitude and phase of an oscillation to be described as a function of time. The basic idea of this method and its application to the quasi-2-day wave is described in detail by Harris and Vincent (1993) and Thayaparan et al. (1997a).

\section{Results}

\subsection{Mean zonal wind}

The focus of this paper is on characteristics of the planetary waves, but to set the results in context we first consider the behaviour of the mean zonal wind. Figure 1 shows a timeheight cross section of the smoothed mean zonal wind (by 10-day running means) between 5 October 2001 and 30 April 2002. The thick solid line indicates zero velocity. The white regions indicate missing data, a 14-day interval in the second half of November 2001 and an 8-day interval at the beginning of January, 2002, obtained because of an interruption in data recording. It is evident that most of the time the wind is westward with a strong maximum in March/April reaching $-90 \mathrm{~m} / \mathrm{s}$ at altitudes around $85 \mathrm{~km}$ and a secondary maximum in October. During the equinoctial months, the zonal wind is westward in the whole altitude range, while in November it is westward only at the altitudes higher than $85 \mathrm{~km}$ and in December only below $90 \mathrm{~km}$. During these two months, a strong wind shear with opposite sign is apparent. The wind is eastward almost in the whole altitude range at the end of December and January, with maximum in January reaching $10 \mathrm{~m} / \mathrm{s}$ at $85 \mathrm{~km}$ height. There is a signature for downward descent of the wind contours which is a characteristic of wave driven circulation. 


\section{ZONAL WIND; ASCENSION ISLAND}
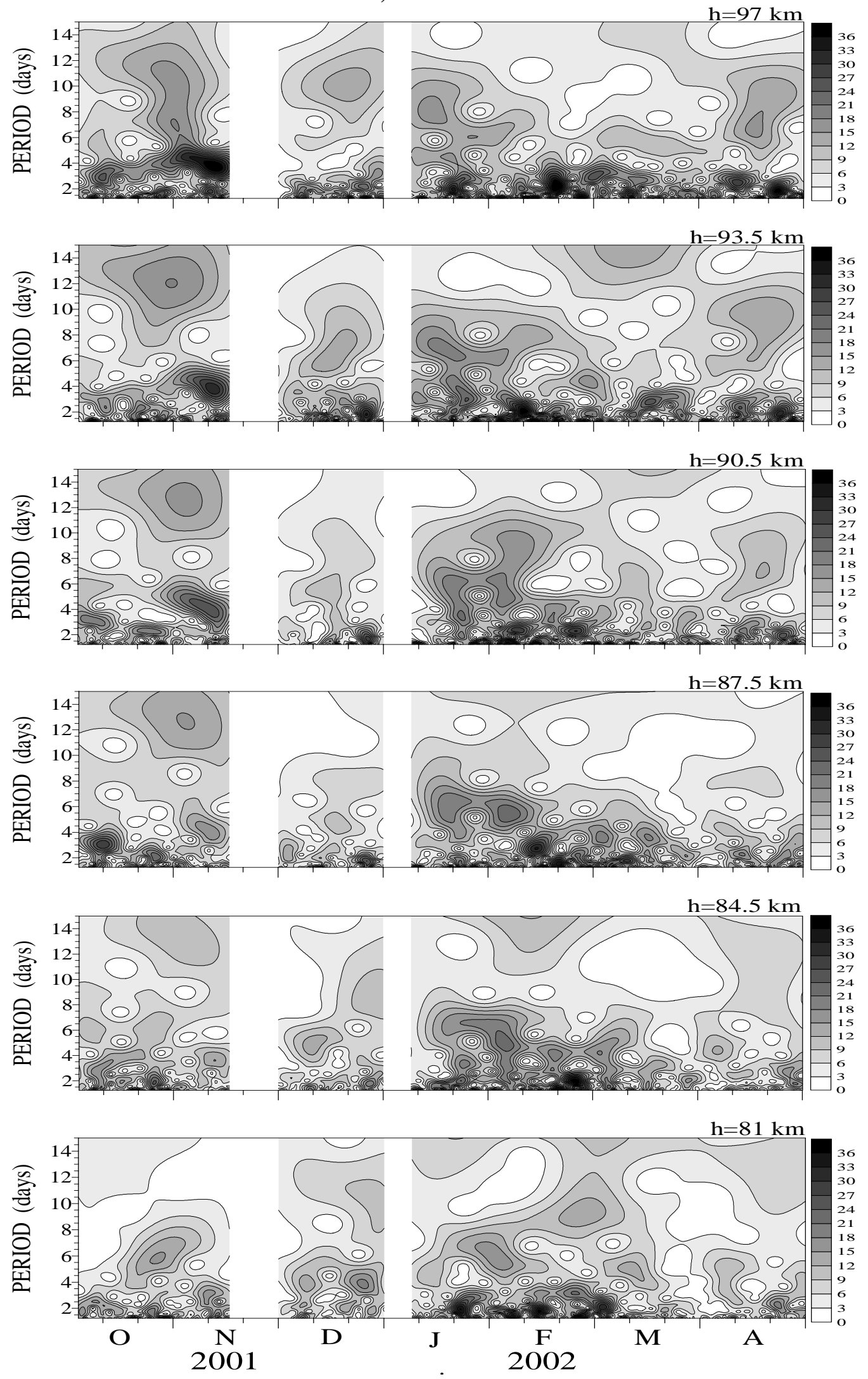

Fig. 2a. Wavelet transform of the zonal wind observed by meteor radar in the interval 05 October 2001-30 April 2002. The spectra are calculated in the period interval 1.5-15 days and for six altitudes shown on the right upper corner of each figure. 

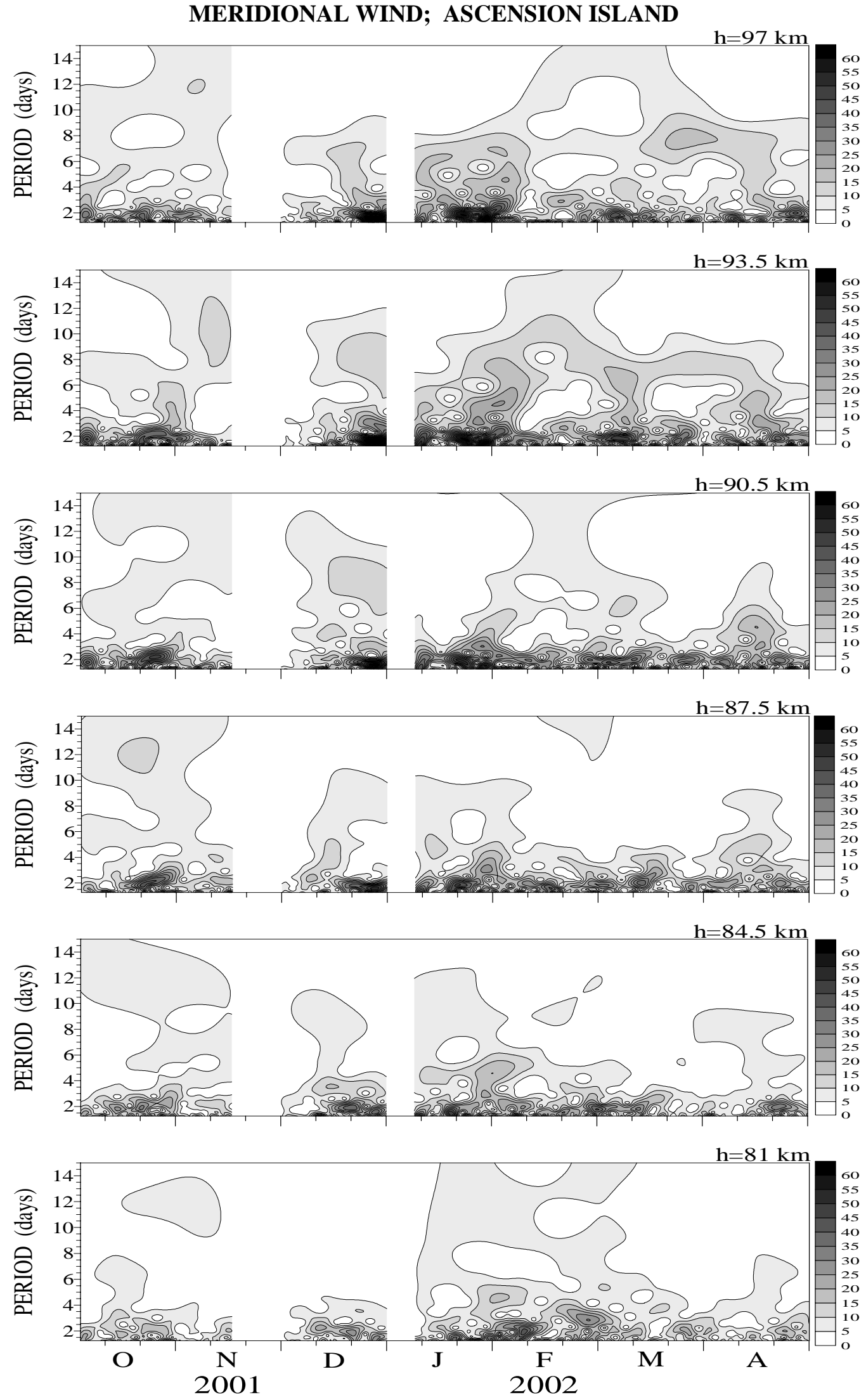

Fig. 2b. The same as Fig. 2a, but for the meridional wind. 

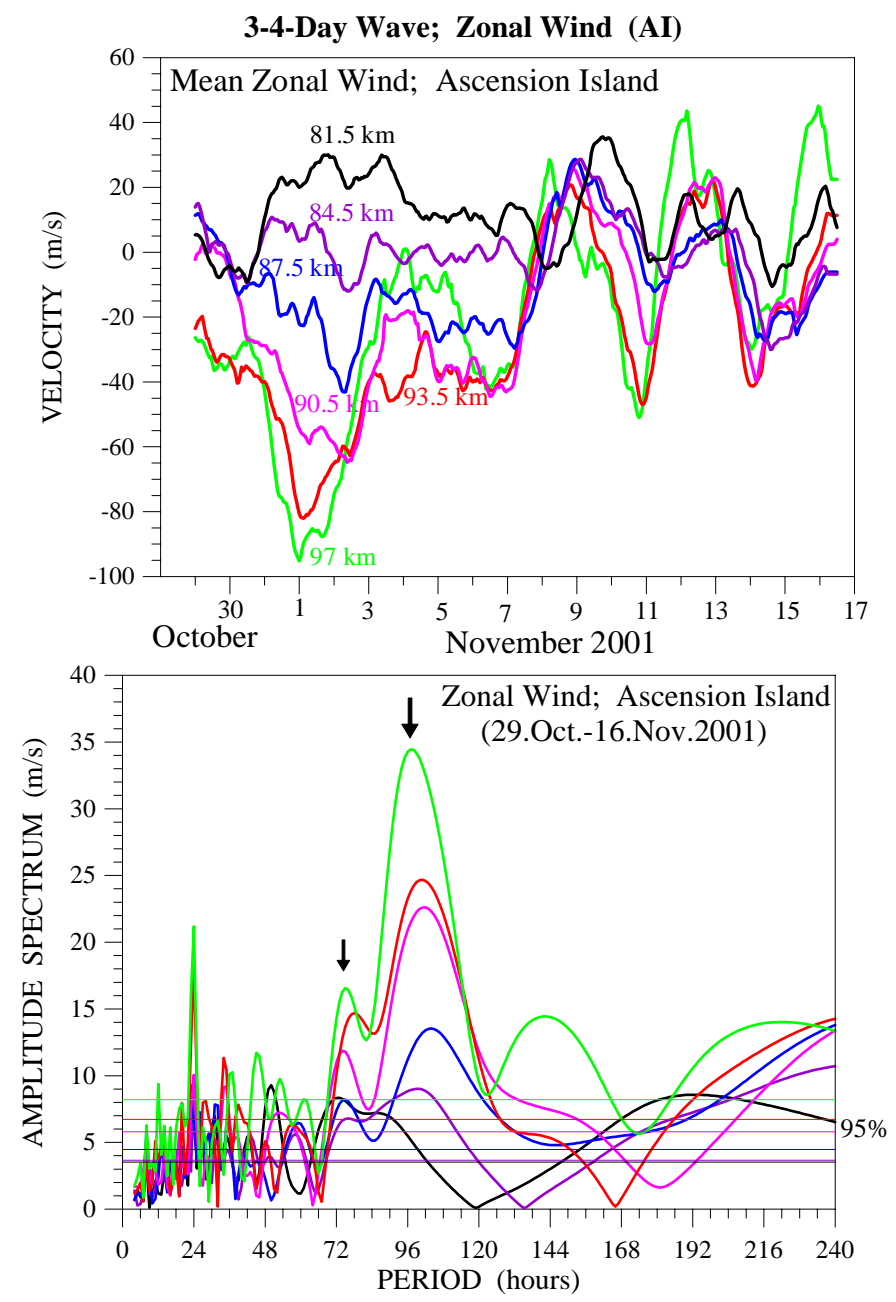

Fig. 3. Variability of the mean zonal winds observed at six altitudes indicated by different colours (black for $\mathrm{h}=81 \mathrm{~km}$; purple for $\mathrm{h}=84.5 \mathrm{~km}$; blue for $\mathrm{h}=87.5 \mathrm{~km}$; magenta for $\mathrm{h}=90.5 \mathrm{~km}$; red for $\mathrm{h}=93.5 \mathrm{~km}$ and green for $\mathrm{h}=97 \mathrm{~km}$ ) during the interval 29 Oct.16 Nov. 2001 (upper panel). Amplitude spectra of the zonal winds observed in the same time interval and calculated from the hourly data by the correloperiodogram analysis. The examined peaks centred at 3 and 4 days are marked by arrows (bottom panel).
3.2 General picture of planetary wave activity between October 2001 and April 2002

Figure 2a presents the wavelet transform of the hourly-mean zonal wind measured at six altitudes shown at the right upper corner of each plot. The strongest oscillation observed at all altitudes is a 3-4-day wave evident at the end of October/November 2001. Its amplitude increases with altitude and reaches a maximum of $42 \mathrm{~m} / \mathrm{s}$ (the observed velocities are limited or "clipped" to be less than $36 \mathrm{~m} / \mathrm{s}$, in order to reduce the dynamic range at all altitudes for plotting purposes). At the end of October/November a 12-13-day wave is also evident at almost all altitudes. The next strong oscillation evident at all altitudes is that observed in January/early February with a period of $\sim 6-7$ days. Its amplitude reaches a maximum of $24 \mathrm{~m} / \mathrm{s}$ at altitude $87.5 \mathrm{~km}$. There are a few strong 2-day wave bursts, but they do not show coherent behaviour with height. We will study in detail the 3-4-day wave evident at the end of October/November, 2001 and the 6-7day wave in January/February 2002.

Figure $2 b$ presents the wavelet transform of the mean meridional wind. The dominant feature of the meridional wind component is the quasi-2-day wave. This seems to be present almost continuously, but the strongest bursts are observed mainly in December/January. The amplitude of the quasi-2-day wave reaches a maximum of $90 \mathrm{~m} / \mathrm{s}$ (the observed velocities are clipped to be less than $60 \mathrm{~m} / \mathrm{s}$ ). We will study all 2-day wave bursts evident in the entire altitude range, but the results for only three of them (the strongest bursts) will be shown.

\subsection{Zonal winds}

\subsubsection{3-4-day wave observed at the end of Octo- ber/November 2001}

The strongest oscillation observed in the zonal winds at the end of October/November, well apparent in Fig. 2a, is the 3-4-day wave. The upper plot of Fig. 3 shows the variability of the mean zonal winds observed at six altitudes, indicated by different colours (black for $\mathrm{h}=81 \mathrm{~km}$; purple for $\mathrm{h}=84.5 \mathrm{~km}$; blue for $\mathrm{h}=87.5 \mathrm{~km}$; magenta for $\mathrm{h}=90.5 \mathrm{~km}$; red for $h=93.5 \mathrm{~km}$ and green for $\mathrm{h}=97 \mathrm{~km}$; the same colour indications for different altitudes are used in all figures), during the end of October/November, 2001. The 3-4-day wave 


\section{3- and 4- Day Wave Characteristics; Zonal Wind (AI) 29 October - 16 November 2001}
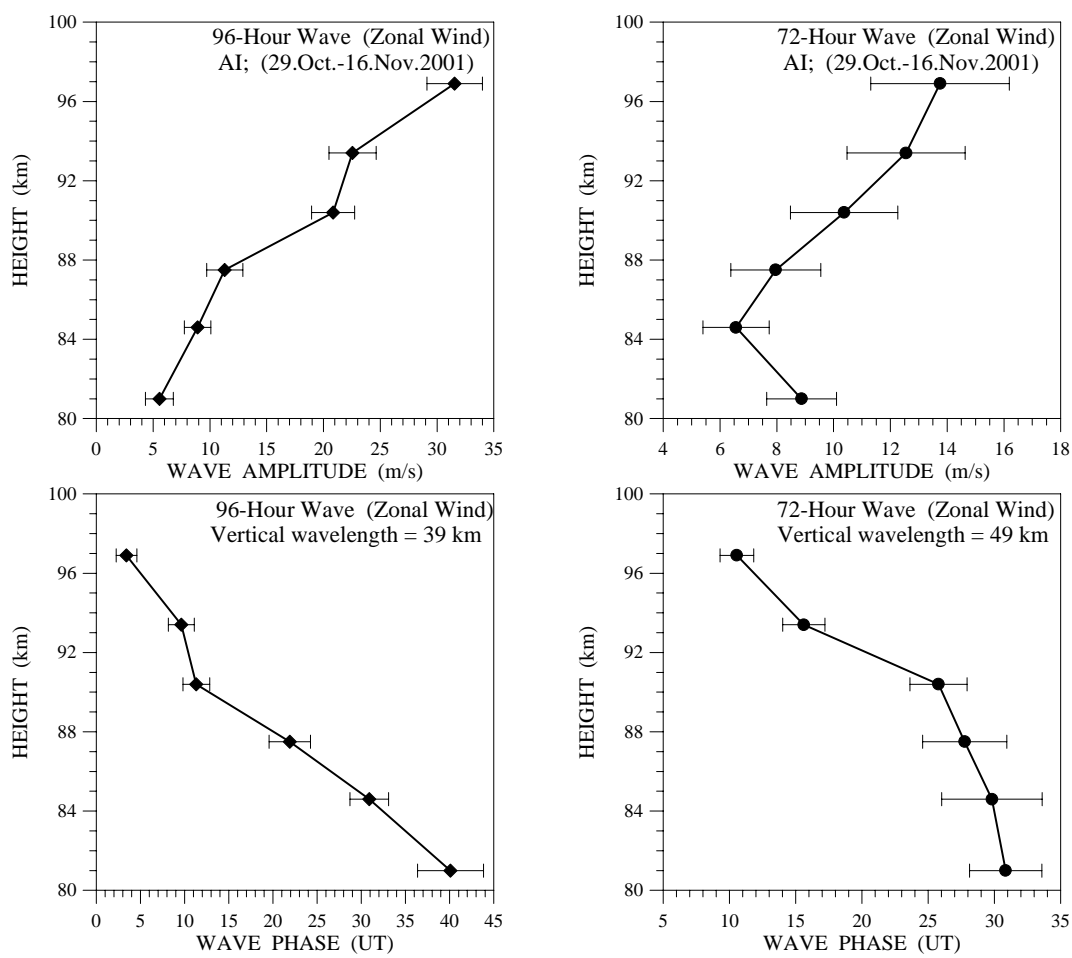

Fig. 4. Least squares amplitude (upper row) and phase (lower row) best fits for waves with periods 72 and $96 \mathrm{~h} \mathrm{ob-}$ served during 29 Oct.-16 Nov. 2001 Error bars indicate the $67 \%$ confidence.

is well evident and its vertical propagation could be clearly noticed, especially around 7 November, when the wave is well developed at all altitudes. The amplitude spectra of the zonal winds at all altitudes observed in the time interval 29 October-16 November 2001 and calculated from the hourly data by the correloperiodogram analysis (Kopecky and Kuklin, 1971) are shown on the bottom plot. The spectra were calculated after the parabolic trend was removed. Two peaks are well indicated, a stronger one at 4 days and another at 3 days (both peaks are marked by arrows). The 95\% confidence level for all altitudes are shown as well. The 4-day wave is very strong, even stronger than the diurnal tide during the investigated time interval, and its amplitude increases significantly with height. The vertical wavelength of the 3 - and 4-day wave is estimated by the change in phase with height. To determine the amplitudes and phases of these waves, a best-fit procedure was applied to the mean hourly data of the above time interval studied. The height profiles of the amplitude and phase of the 4-day wave are shown on the left side of Fig. 4, while the respective profiles for the 3-day wave are shown on the right side of the same figure. Both waves are vertically propagating, and the vertical wavelength of the 4day wave is found to be $39 \mathrm{~km}$, while that of the 3-day wave is $49 \mathrm{~km}$.
3.3.2 The 3- and 6-day waves observed in January/February 2002

The next oscillation that is outlined well in the wavelet spectra of the zonal winds (Fig. 2a) is the 6-7-day wave during January/February 2002. The upper plot of Fig. 5 shows the variability of the mean zonal winds observed at six altitudes during January/early February 2002. There are four well outlined $\sim 6$-day cycles, however, shorter period oscillations are also evident. The bottom plot of Fig. 5 shows the amplitude spectra calculated from the detrended hourly data in the interval 8 January-21 February 2002. It confirms the complicated character of the observed disturbances on the upper plot. Besides the peak at 6.2 days there is also a peak around 3.2 days (periods for the different altitudes are clustered between 76-80 h), as well as an oscillation that is changeable (between $90-115 \mathrm{~h}$ ) with height period. The applied best fit procedure included all three oscillations, however, the result for the 4-5-day wave was not stable, probably because the period was too variable at different altitudes. The height profiles of the amplitude and phase of the 3.2-day wave are shown on the left side of Fig. 6, while the respective profiles for the 6.2-day wave are shown on the right side of the same figure. Again, both waves are vertically propagating, and the vertical wavelength of the 3.2-day wave is $50 \mathrm{~km}$, or the same as that found for the 3-day wave observed in Octo- 

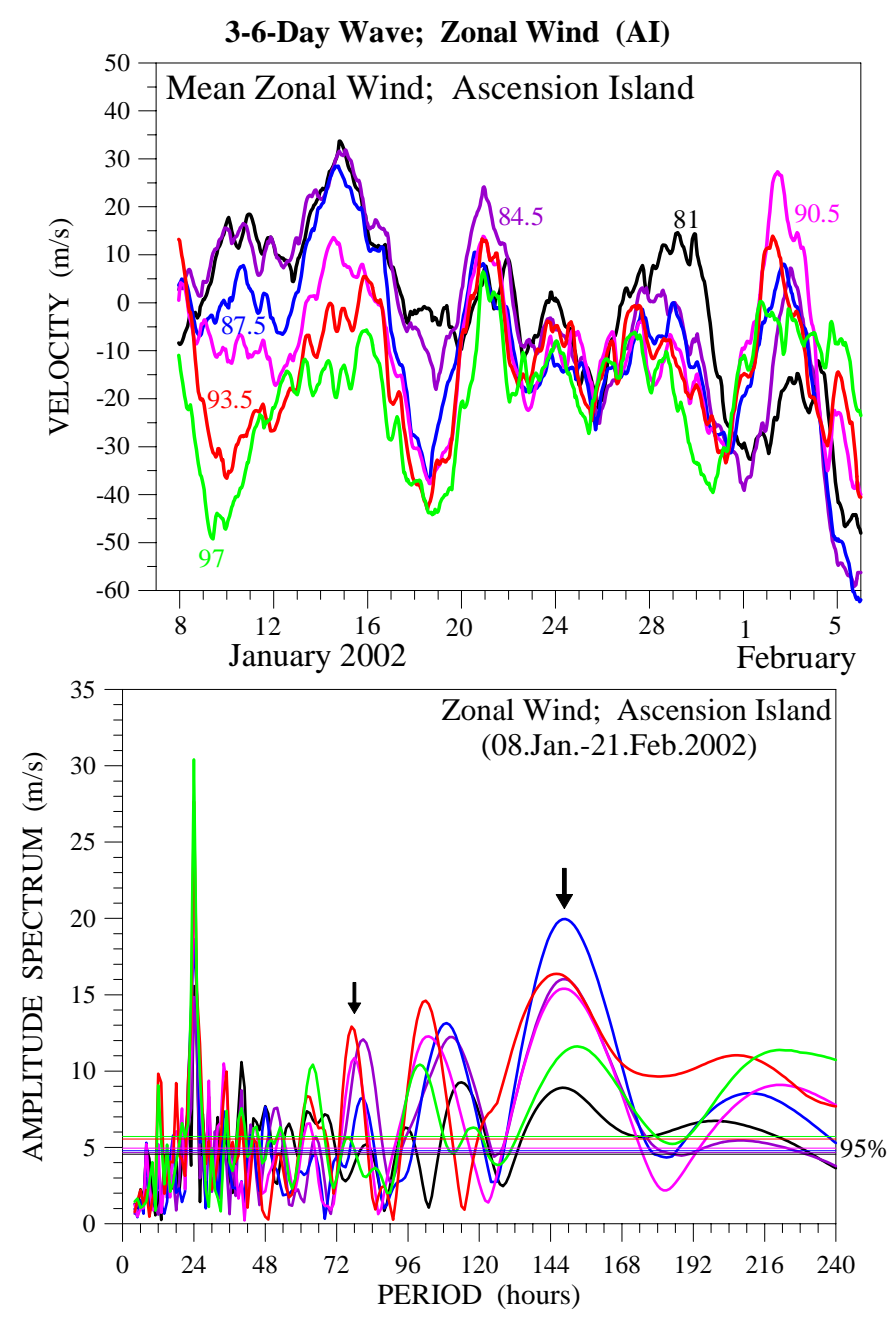

Fig. 5. Variability of the mean zonal winds observed at six altitudes during the interval January/early February 2002 (upper panel). Amplitude spectra calculated from the hourly values of the zonal winds measured at six altitudes during the time interval 08 January-21 February (bottom panel). The examined peaks centred at $\sim 3$ and 6 days are marked by arrows.
ber/November 2001. The vertical wavelength of the 6.2-day wave, however, is much longer than that of the 3.2-day wave, and it is estimated to be $79 \mathrm{~km}$.

\subsection{Quasi-2-day wave in the meridional winds}

We will study the quasi-2-day wave observed only in the meridional winds because their amplitudes are at least two times larger than those in the zonal winds and because the observed oscillations in the zonal winds rarely show coherent behaviour with height (an exception is the quasi-2-day wave observed in the zonal winds at all altitudes during the end of December 2001). It is known from previous observations that the period of the quasi-2-day wave changes mainly between 40 and $60 \mathrm{~h}$. To study in detail the variability of the period of the 2-day wave, we perform again the wavelet transform on the hourly meridional wind but in the period range between 30 and $72 \mathrm{~h}$. The result is shown in Fig. 7 (the observed velocities are again clipped to be less than $60 \mathrm{~m} / \mathrm{s}$ ). The period of the quasi-2-day wave observed above Ascension Island during the time interval studied changes between 1.5 and 2.5 days. Several bursts centred around the second half of October, the end of December, January/early February, beginning of March and the end of April are well apparent at all altitudes. All of them are investigated but detail results will be shown only for the first three of them.

The upper plot of Fig. 8a shows the amplitude spectra for all altitudes calculated from the hourly meridional wind measured during 5 October-16 November 2001. Two peaks around 43 and $51 \mathrm{~h}$ are evident. To evaluate the temporal variation of the amplitudes of the quasi-2-day waves, the method of complex demodulation (Bloomfield, 1976) was applied. An effective band-pass filter was used with limits from 40 to $58 \mathrm{~h}$ for the 48 -h demodulation period. The bottom plot of figure 8 a shows the temporal variation of the instantaneous amplitudes of the quasi-2-day waves observed in the meridional wind at all altitudes. The waves are strong between 15 October-5 November 2001. Figure $8 \mathrm{~b}$ shows the time-height cross section of the mean meridional wind observed during 15 Oct.-5 Nov. 2001. The quasi-2-day waves with amplitudes larger than $30 \mathrm{~m} / \mathrm{s}$ and with downward phase velocity are well evident without any filtration of data. The vertical profiles of the amplitude and phase of the 51-h wave are shown on the left side of Fig. 9, while those of the 43-h 


\section{3- and 6-Day Wave Characteristics; Zonal Wind (AI) 08 January - 21 February 2002}
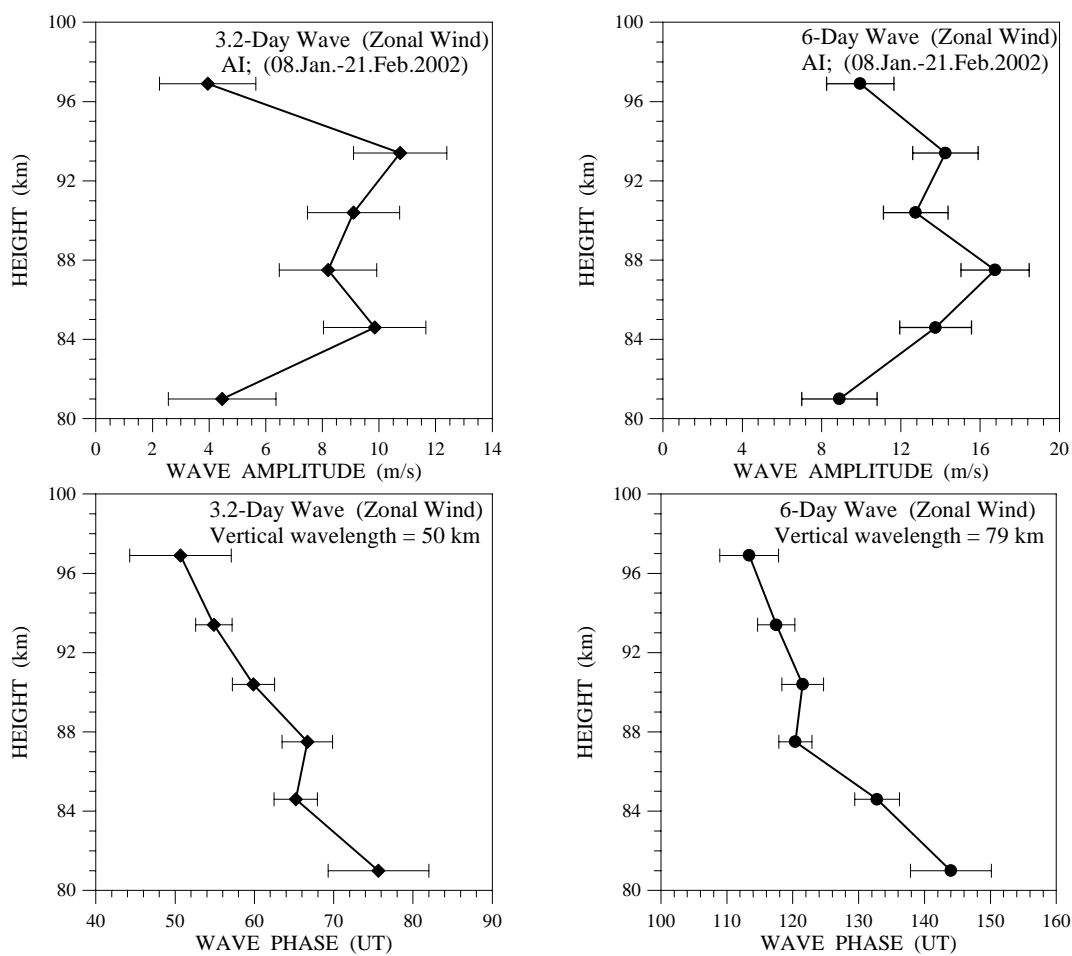

Fig. 6. Least-squares amplitude (upper row) and phase (lower row) best fits for waves with periods 3.2 and 6 days observed during 8 Jan.-21 Feb.2002. wave are shown on the right side. The vertical wavelengths of both waves are very close, $31 \mathrm{~km}$ and $25 \mathrm{~km}$ for the 51 and 43-h wave, respectively.

According to Fig. 7 the strongest 2-day wave burst is evident in the second half of December 2001, with a mean period shorter than $48 \mathrm{~h}$. The upper plot of Fig. 10 shows the amplitude spectra of the meridional wind for December 2001. Two peaks in the quasi-2-day range are well evident. The stronger peak has a period of $40 \mathrm{~h}$ and its mean amplitude during the whole month is $\sim 25 \mathrm{~m} / \mathrm{s}$, however, the instantaneous amplitude found by complex demodulation or the amplitude from the wavelet transform reaches maximum of $\sim 90 \mathrm{~m} / \mathrm{s}$. The second peak is situated at $50 \mathrm{~h}$ with mean amplitude for the whole month of $14 \mathrm{~m} / \mathrm{s}$. The bottom plot of Fig. 10 shows the time-height cross section of the mean meridional wind between 16-31 December. Both waves can be distinguished from this plot. The longer period 2-day wave $(\sim 50 \mathrm{~h})$ is evident between 16-23 December, while the shorter one $(\sim 40 \mathrm{~h})$ can be observed later. The vertical slope of phase velocity for the 50-h wave is higher than that for the 40-h wave. The vertical profiles of the amplitude and phase of the 40-h wave are shown on the left side of Fig. 11, while those of the 50-h wave are shown on the right side. The vertical wavelengths of both waves are very different, $85 \mathrm{~km}$ and $26 \mathrm{~km}$ for the 40 - and 50-h wave, respectively, a result that has been already noticed in the bottom plot of Fig. 10.
The last quasi-2-day wave case study shown in this paper is observed during January/February 2002. The wavelet spectra from Fig. 7 indicate that this event is very complicated and is composed of several different waves. The upper plot of Fig. 12 shows the amplitude spectra of the meridional wind calculated from the detrended data in the interval 8 January-7 February 2002. Five peaks are clearly indicated with periods $34,43,48,54$ and $67-70 \mathrm{~h}$ and the strongest peaks are those at 48 and $34 \mathrm{~h}$. The bottom plot of Fig. 12 again shows the time-height cross section of the mean meridional wind observed in the studied interval. The variability of the meridional wind is very strong; it changes from northward $70 \mathrm{~m} / \mathrm{s}$ to southward $-40 \mathrm{~m} / \mathrm{s}$. Downward phase velocities with different slopes are evident on this plot. The results from the best fit analysis only for the vertically upward propagating 2-day waves in the entire altitude range are shown in Fig. 13. These are waves with periods $34,43,48$ and $54 \mathrm{~h}$, while the result for the 67-70-h wave (not shown here) indicates vertically upward propagation only above $87-88 \mathrm{~km}$. The vertical wavelengths of upward propagating 43-, 48- and 54-h waves are commensurable (with lengths, respectively, $47 \mathrm{~km}, 50 \mathrm{~km}$ and $48 \mathrm{~km})$, while that for the $34-\mathrm{h}$ wave is significantly shorter $(31 \mathrm{~km})$. 


\section{QUASI-2-DAY WAVE (MERIDIONAL WIND) ASCENSION ISLAND}
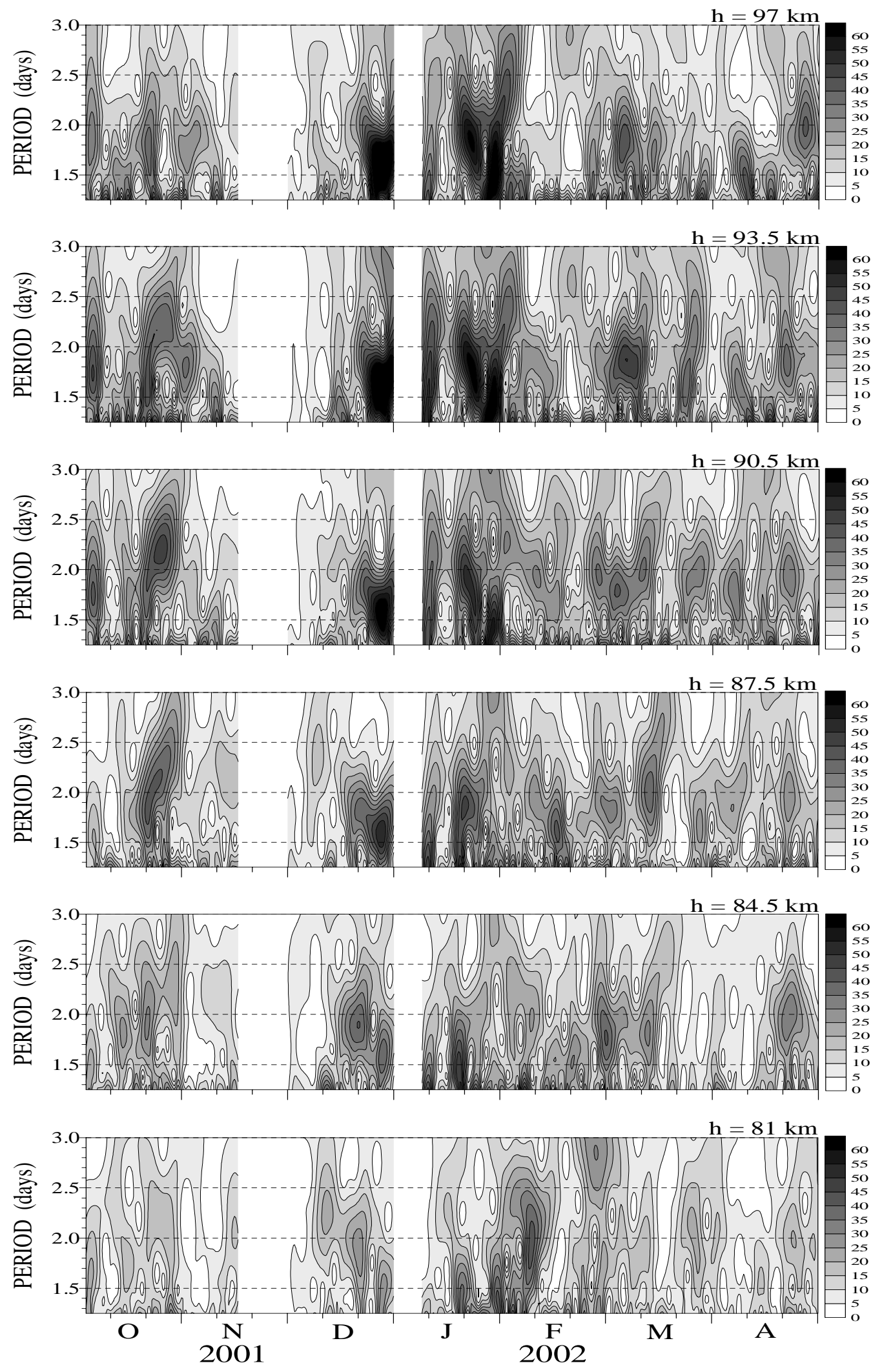

Fig. 7. Wavelet transform of the meridional wind observed by meteor radar in the interval 05 Oct. 2001-30 Apr. 2002. The spectra are calculated in the period interval $30-72 \mathrm{~h}$ and for six altitudes. 

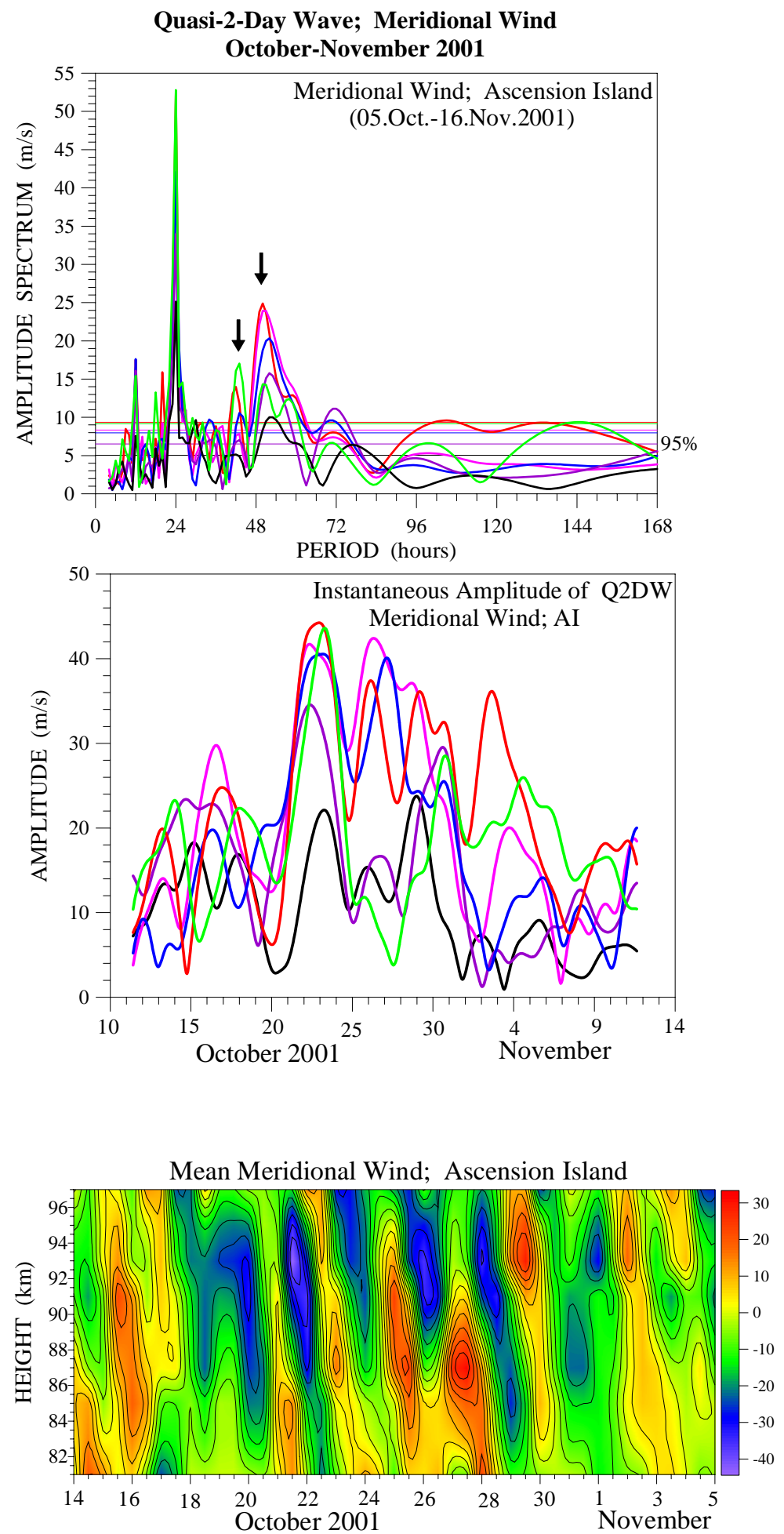

Fig. 8a. Amplitude spectra calculated from the hourly values of the meridional winds measured at six altitudes during the interval 5 Oct.-16 Nov. 2001 (upper panel). The studied peaks centred at 43 and $51 \mathrm{~h}$ are marked by arrows. Amplitudes of the quasi-2-day waves obtained by the complex demodulation method and observed at six different altitudes are shown on the lower panel.

Fig. 8b. Time-height cross section of the mean meridional wind observed during 15 Oct. -5 Nov. 2001. The quasi2-day waves with downward phase velocity are well evident.

\section{Discussion}

The first results of the planetary wave characteristics observed by meteor radar above Ascension Island during October 2001-April 2002 are reported in this paper. Two "case studies" of 3-7-day waves observed in the zonal wind and several 2-day wave bursts in the meridional wind are described in detail.

Wavelet analysis of motions in the 3-10 day period range shows a predominance of energy in the zonal component (Fig. 2). This behaviour is frequently ascribed to the presence of Kelvin waves in the equatorial atmosphere. Kelvin 


\section{Quasi-2-Day Wave Characteristics; Meridional Wind (AI) October - November 2001}
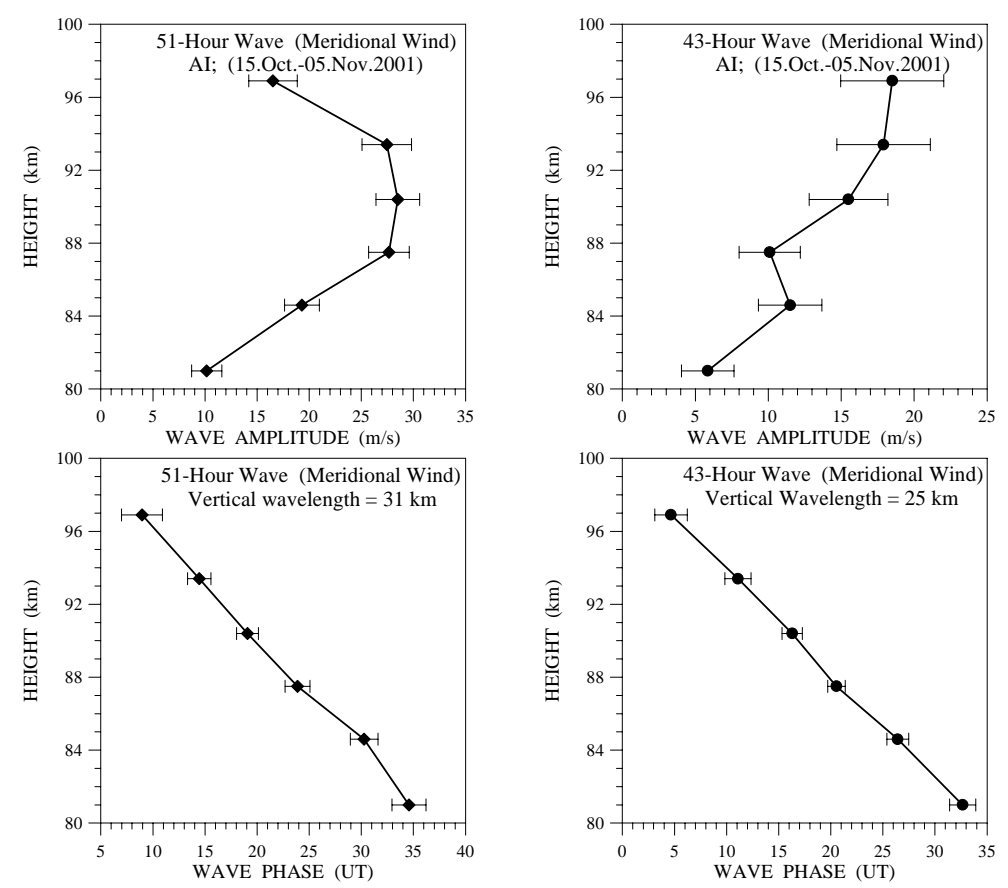

Fig. 9. Least-squares amplitude (upper row) and phase (lower row) best fits for waves with periods 51 and $43 \mathrm{~h}$ observed during 15 Oct. -5 Nov. 2001 waves are equatorially trapped, eastward propagating waves that cause oscillations in the zonal wind component only (Andrews et al., 1987). In the longitude-height plane Kelvin waves have the structure of buoyancy waves (Holton, 1992). They have downward (in time) and eastward (in space) phase propagation, which implies upward propagation of energy. The zonal and vertical scales are related to the frequency of Kelvin waves through the dispersion relation of twodimensional gravity waves. Most of their variance is found in zonal wave numbers 1-3. They occur in three discrete speed ranges or, equivalently, three frequency bands. They are defined as: (i) "slow" (or Wallace-Kously) waves, with a phase speed range of 20-40 m/s (or period range 12-20 days) and vertical wavelength of about $10 \mathrm{~km}$ (Wallace and Kousky, 1968); (ii) "fast" waves, with a phase speed of 50$80 \mathrm{~m} / \mathrm{s}$ (period range 6-10 days) and vertical wavelength of $\sim 20 \mathrm{~km}$ (Hirota, 1978), and (iii) "ultra-fast" waves with a phase speed $\sim 120 \mathrm{~m} / \mathrm{s}$ (period range 3-4 days) and vertical wavelength of 40-50 km (Salby et al., 1984; Forbes, 2000).

Figure 3 shows a very strong 3-4-day wave event observed at the end of October and November, unfortunately incomplete because of an interruption in data gathering after 16 November. Spectral analysis shows that this event is composed of two waves: 3- and 4-day waves with increasing height amplitudes, reaching values of $15 \mathrm{~m} / \mathrm{s}$ and $32 \mathrm{~m} / \mathrm{s}$, respectively. Figure 5 presents a "case study" of a 6-7-day wave event observed in January/February, composed of three different waves: 3.2-, 4-5- and 6-day waves. The vertical wavelengths of the 3- and 3.2-day waves are 49 and $50 \mathrm{~km}$, respectively, and they are observable only in the zonal wind component. We are not able to study the zonal structure of these waves, because we have measurements only at a single point, but the obtained vertical wavelengths and the fact that these 3- and 3.2-day waves exist only in the zonal component suggests the signature of an ultra-fast Kelvin wave. A few papers published recently have been devoted to the observational characteristics of the ultra-fast Kelvin waves and especially to their vertical wavelength. Vincent (1993) found that over Christmas Island the 3.5-day Kelvin wave has a mean vertical wavelength of $\sim 65 \mathrm{~km}$ and later Kovalam et al. (1999), investigating longer period observations at the same place, clarified that the vertical wavelength varies between 53 and $88 \mathrm{~km}$. Riggin et al. (1997) investigated the waves with a period of $\sim 3$ days over Christmas Island and Jakarta during January-October 1993 and found that they have very long vertical wavelengths. This probably suggests that the wave was predominantly a zonal wave number 1 . Sridharan et al. (2002) found that the vertical wavelength for the 3.2-3.7-day wave observed over Tirunelveli lies mostly in the range $30-60 \mathrm{~km}$. Despite the relatively short data set, the obtained results in this paper for the vertical wavelength of the 3- and 3.2-day waves are in reasonable accord with earlier observations and are very close to the numerical modelling results (Forbes, 2000). The 4-day wave with amplitude larger than $30 \mathrm{~m} / \mathrm{s}$ is the strongest wave observed in the zonal wind during the studied time interval. The estimated vertical wavelength is $39 \mathrm{~km}$. It resembles the typical wavelengths of the ultra-fast Kelvin wave (Salby et al., 1984). As sim- 
Quasi-2-Day Wave; Meridional Wind (AI) December 2001

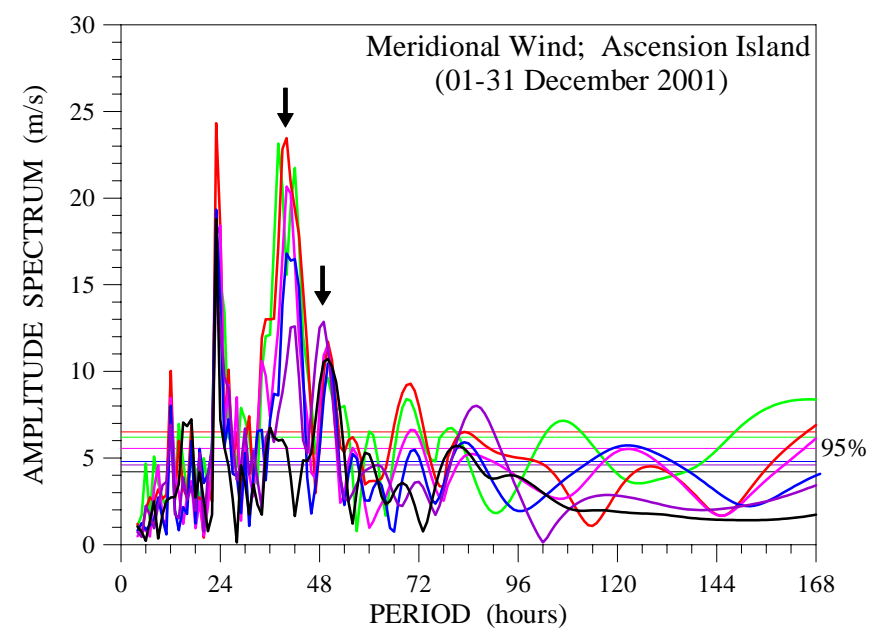

Mean Meridional Wind; Ascension Island

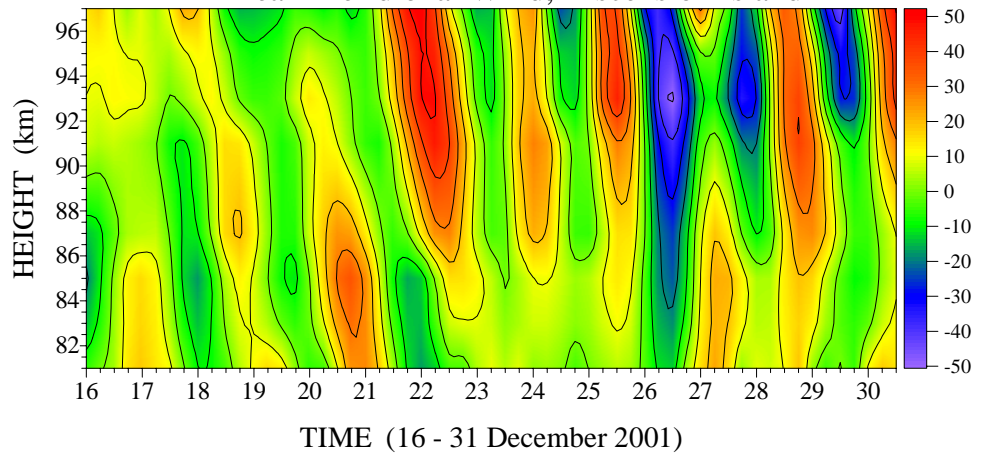

Fig. 10. Amplitude spectra calculated from the hourly values of the meridional winds measured at six altitudes during the interval 1-31 December 2001 (upper panel). The investigated peaks centered at 40 and $50 \mathrm{~h}$ are marked by arrows. Time-height cross section of the mean meridional wind observed during 15-31 Dec. 2001 is shown on the lower panel. ilar waves are completely absent in the meridional wind at the end of October/November, we may assume that the 4day wave is an ultra-fast Kelvin wave. However, the 4-day wave could also be a normal $(2,1)$ mode. Isoda et al. (2002) observed a 4-day wave above Pontianak and Christmas Island during the July/August period, which was identified as a global-scale westward propagating normal mode with zonal wave number 2. As we do not have any information about the zonal structure of this wave, in order to check these two possibilities, we can use some information about the planetary wave activity in the stratosphere. The preliminary analysis of United Kingdom Meteorological Office (UKMO) assimilated geopotential height at $1 \mathrm{hPa}$ pressure level (altitude of about $50 \mathrm{~km}$ ) for 2001 above the equator does not show substantial amplification of the 4-day eastward propagating wave with zonal wave number 1 (A. Pogoreltsev, private communication). At the same time there is some amplification of the normal mode $(2,1)$ 4-day wave at mid-latitudes in November. According to Pogoreltsev et al. (2002) it suggests that this mode could be observed in the zonal wind at the low latitude MLT region as well. If the normal $(2,1)$ mode 4day wave exists in the geopotential height at the mid-latitude stratosphere it could also be observed in the meridional midlatitude MLT region (Pogoreltsev et al., 2002). The prelimi- nary analysis of the meridional wind at Collm $\left(52^{\circ} \mathrm{N}\right)$ and at the high latitude station ESRANGE $\left(68^{\circ} \mathrm{N}\right)$, however, does not show the presence of 4-day wave in November. We have to mention, however, that the UKMO data are daily averaged data and are not so reliable for studying the 4-day wave. Consequently, on the basis of available information for the 4-day wave observed at the end of October/November, we cannot make a firm decision about the origin of this wave. It resembles the ultra-fast Kelvin wave with respect to its very large amplitude (more than $30 \mathrm{~m} / \mathrm{s}$ ) and to its short vertical wavelength (usually the normal mode planetary waves have larger than $40 \mathrm{~km}$ vertical wavelength). Such Kelvin waves, however, have not been found in the equatorial stratosphere (A. Pogoreltsev, private communication).

The significant role of the equatorial Kelvin waves in producing the zonal mean eastward flow was mentioned above. The zonal eastward acceleration is given by the convergence of the vertical flux of horizontal momentum. Following the approach of Kovalam et al. (1999) (actually based on the Riggin et al., 1997 method) we made some preliminary calculations for the body force per unit mass for the 3- and 3.2day waves which are interpreted here as ultra-fast Kelvin waves. It was found that the eastward forcing provided by these waves around height $93.5 \mathrm{~km}$ is, respectively, $\sim 0.24$ 

Qasi-2-Day Wave Characteristics; Meridional Wind (AI)
15-31 December 2001
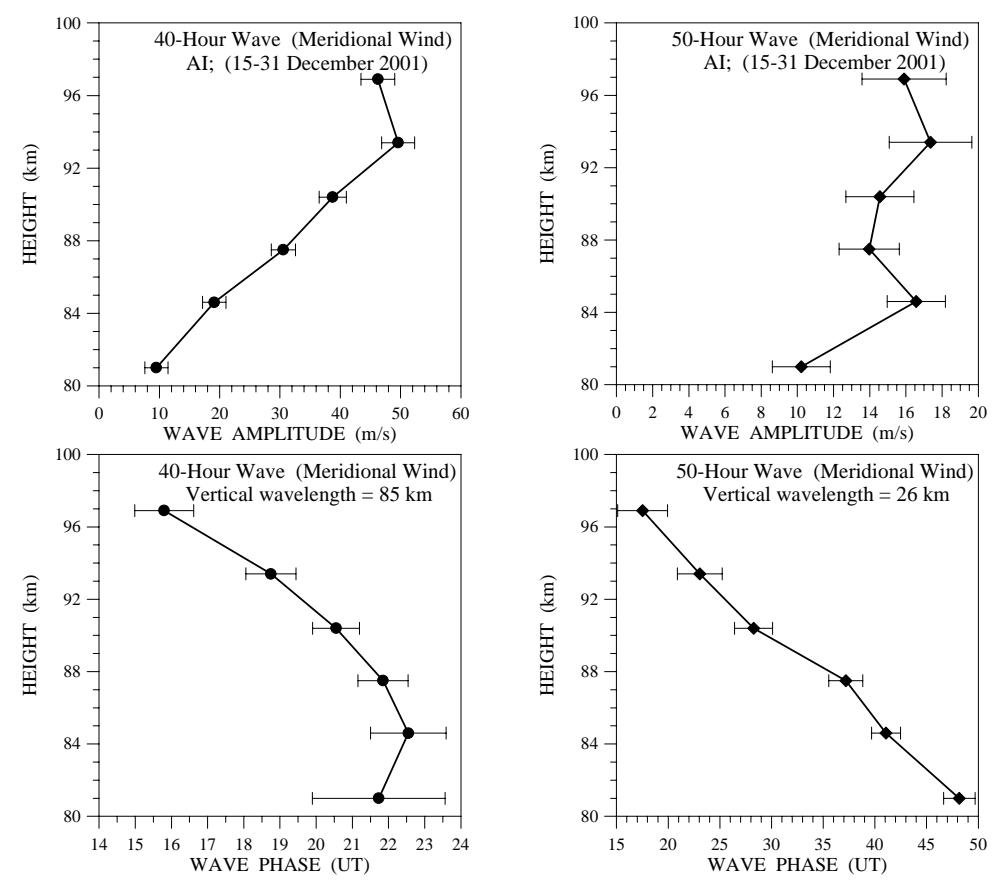

Fig. 11. Least-squares amplitude (upper row) and phase (lower row) best fits for waves with periods 40 and $50 \mathrm{~h} \mathrm{ob}$ served during 15-31 Dec. 2001. and $\sim 0.21 \mathrm{~m} / \mathrm{s}^{-1} \mathrm{day}^{-1}$; consequently, it is not sufficient enough to produce net eastward motion of the background atmosphere. If we assume that the 4-day wave observed at the end of October/November can be interpreted as an ultra-fast wave number 1 Kelvin wave, then its mean eastward forcing is significantly stronger, $\sim 1.33 \mathrm{~m} / \mathrm{s}^{-1}$ day $^{-1}$, and could play some role in the momentum budget. This eastward acceleration is similar to that found by Kovalam et al. (1999) for Pontianak in May 1996 and significantly stronger than monthly mean accelerations obtained for Christmas Island. This acceleration is also stronger than the monthly mean accelerations found by Sridharan et al. (2002) for Tirunelveli.

The 6-day wave observed in January/February has a maximum amplitude of $16-18 \mathrm{~m} / \mathrm{s}$ at heights below $90 \mathrm{~km}$ and a very large vertical wavelength of $79 \mathrm{~km}$. This large wavelength does not correspond to the Kelvin wave interpretation. The zonal wave number 1 fast Kelvin waves have an intrinsic phase speed of less than $100 \mathrm{~m} / \mathrm{s}$, which means vertical wavelengths shorter than $25-30 \mathrm{~km}$. Therefore, probably the observed 6-day wave is a Doppler-shifted 5-day normal mode. The summarised characteristics of the quasi-2day wave bursts observed in the meridional wind are presented in Table 1. This wave seems to be present almost continuously, but the strongest bursts are observed mainly in December and January (Fig. 7). The 2-day waves are a dominant feature of the meridional wind above Ascension Island, indicating the upward transport of energy. The events considered here are evident very well without any filtering of the data. The observed period range is large, from 34 to $68 \mathrm{~h}$, with some clustering around 43-44 and $50 \mathrm{~h}$. Similar results were obtained by earlier observations. Harris and Vincent (1993) found that the predominant periods above Christmas Island are 44 and $50 \mathrm{~h}$, but in January/February the period shifts to $48 \mathrm{~h}$. Gurubaran et al. (2001) obtained periods between 46 and $53 \mathrm{~h}$ over Tirunelveli with seasonal dependence. The earlier calculations of the vertical wavelength during the solstices (from the rate of change of phase with height) are found to range from 20 to more than $150 \mathrm{~km}$. Our estimates for the vertical wavelength indicate shorter lengths during the equinoxes, in the range of $25-30 \mathrm{~km}$, and longer ones, $\sim 40-50 \mathrm{~km}$, in January/February, when the 48$\mathrm{h}$ wave is the strongest. Craig et al. (1980) found recurring vertical wavelength of $\sim 50 \mathrm{~km}$ observed above Townsville $\left(19^{\circ} \mathrm{S}, 147^{\circ} \mathrm{E}\right)$ during December/January. Palo and Avery (1995) also found similar results for the vertical wavelength of the quasi-2-day wave in January/February above Christmas Island; it varies between 36 and $44 \mathrm{~km}$ when the period approaches $48 \mathrm{~h}$. Although the zonal wave number cannot be determined from a single station, the lack of power in the zonal wind near $48 \mathrm{~h}$ in January/February and the estimated similar vertical wavelengths apparent at other equatorial sites are consistent with the $(3,0)$ Rossby-gravity normal mode associated with the quasi-2-day wave. Harris and Vincent (1993), however, reported a longer, $\sim 70 \mathrm{~km}$, mean vertical wavelength observed in December above Christmas Island. We also a observed very strong 40-h wave with very large $(85 \mathrm{~km})$ vertical wavelength in December, but we found at this time a $50-\mathrm{h}$ wave with very short $(26 \mathrm{~km})$ vertical 
Quasi-2-Day Wave; Meridional Wind (AI) January - February 2002
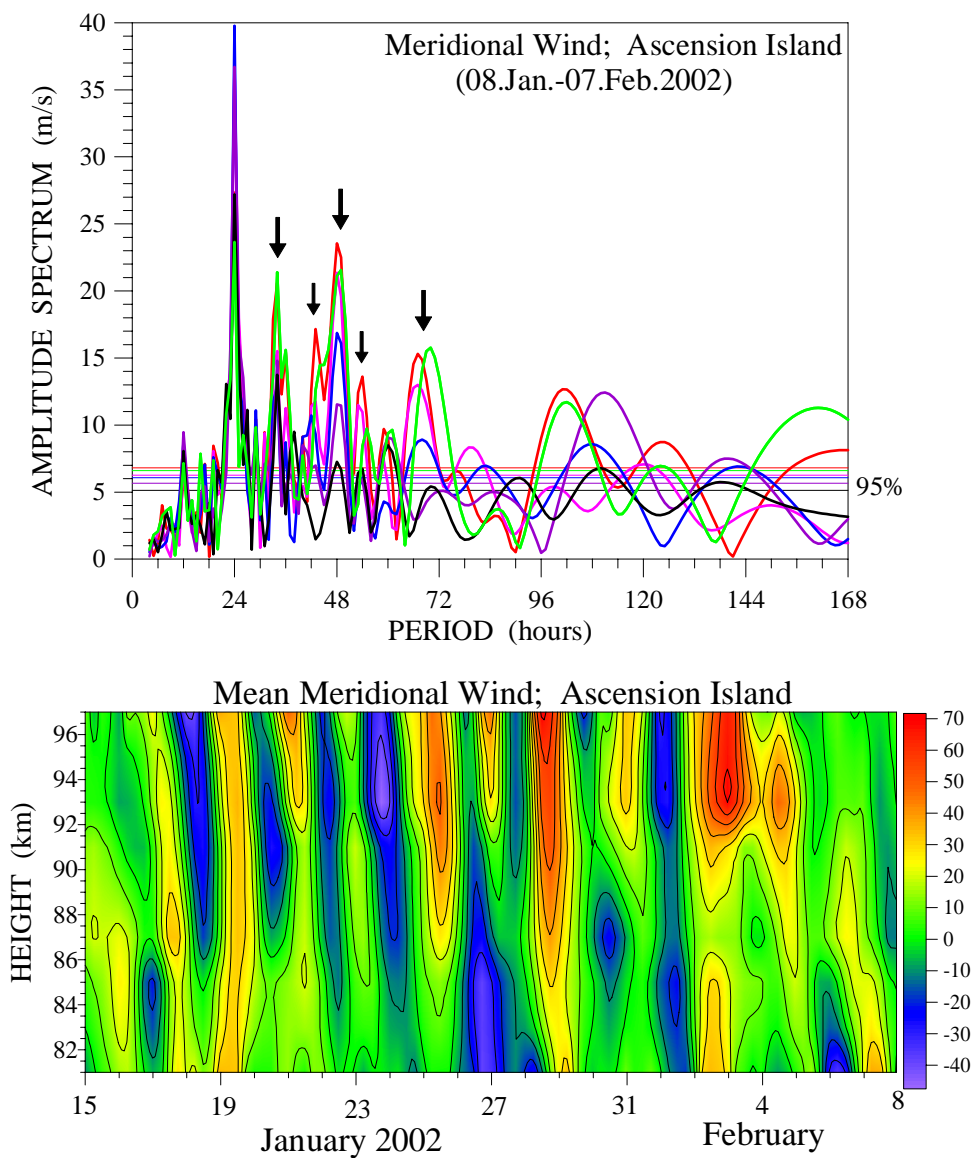

Fig. 12. Amplitude spectra calculated from the hourly values of the meridional winds measured at six altitudes during the interval 8 Jan.-7 Feb. 2002 (upper panel). The investigated peaks centred at $34,43,48,54$ and $67-70 \mathrm{~h}$ are marked by arrows. Time-height cross section of the mean meridional wind observed during 15 Jan.-7 Feb. 2002 is shown on the lower panel. wavelength as well. We cannot interpret the 40- and 50-h waves observed in December now; we can mention only that there is some power in the zonal wind as well, but only at period $40 \mathrm{~h}$ (Fig. 2a and an additional spectral analysis not shown here).

As mentioned before, the quasi-2-day wave event in January/February is very complicated and is composed of several different waves (upper plot of Fig. 12). The 48-hour wave with vertical wavelength of $50 \mathrm{~km}$ was interpreted as a $(3,0)$ Rossby-gravity normal mode. We also found that at the same time the zonal wind is dominated by the 6-day wave with vertical wavelength $79 \mathrm{~km}$ which was associated with a Doppler-shifted 5-day normal mode. If we assume that there is a nonlinear interaction between both waves, then the sum secondary wave has to have a period of $35 \mathrm{~h}$ and a vertical wavelength of $30.6 \mathrm{~km}$, while the difference secondary wave has, respectively, $72 \mathrm{~h}$ and $135 \mathrm{~km}$. In our case we observe a very strong 34-h wave with vertical wavelength of $31 \mathrm{~km}$ (the same as the sum secondary wave) and a moderate 67-70$\mathrm{h}$ wave with upward propagation but only above $87-88 \mathrm{~km}$. Therefore, this is a signature that at least the 34-h wave observed in January/February could be interpreted as a sum socondary wave.
Table 1. Characteristics (period, maximum amplitude and vertical wavelength) of the quasi-2-day wave observed at Ascension Island (AI) during the interval 05 October 2001-30 April 2002.

\begin{tabular}{cccc}
\hline $\mathrm{t}$ (hours) & Amax $(\mathrm{m} / \mathrm{s})$ & $\begin{array}{c}\text { Vertical } \\
\text { Wavelength }(\mathrm{km})\end{array}$ & Time interval \\
\hline 51 & 30 & 31 & 15 Oct.-5 Nov. 2001 \\
43 & 20 & 25 & \\
40 & 50 & 85 & 15 Dec.-31 Dec 2001 \\
50 & 20 & 26 & \\
34 & 25 & 31 & \\
43 & 20 & 47 & \\
48 & 30 & 50 & \\
54 & 17 & 48 & \\
68 & 18 & - & Jan.-07 Feb 2002 \\
44 & 23 & 26 & 18 Feb.-16 Mar. 2002 \\
46 & 28 & 25 & 15 Apr.-30 Apr. 2002
\end{tabular}

Another interesting feature observed in the meridional wind during the amplification of the quasi-2-day wave is the anti-correlation between the 2-day wave and the diurnal tide (Harris and Vincent, 1993; Gurubaran et al., 2001). Very 

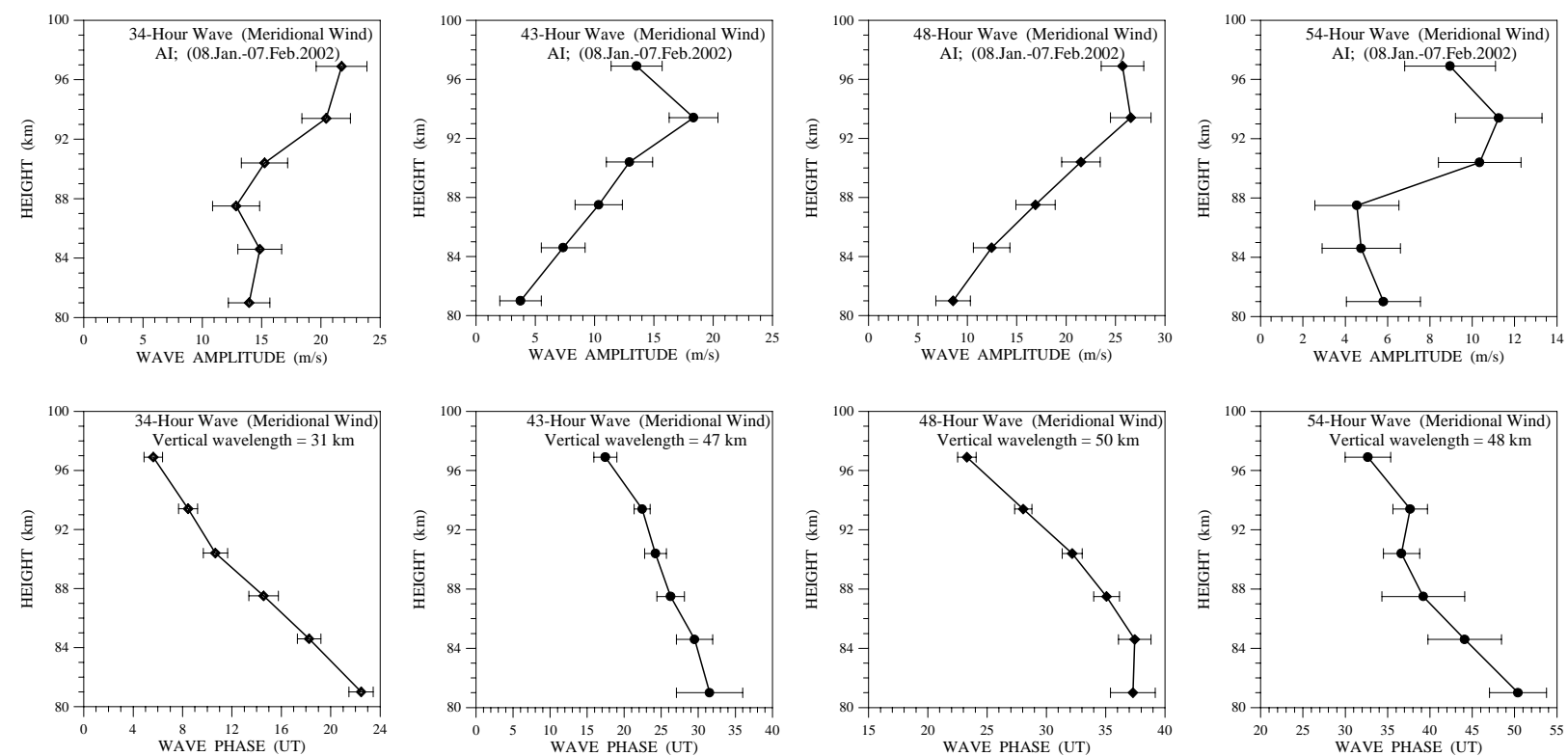

Fig. 13. Least-squares amplitude (upper row) and phase (lower row) best fits for waves with periods 34,43 , 48 and 54 h observed during 8 Jan.-7 Feb. 2002.
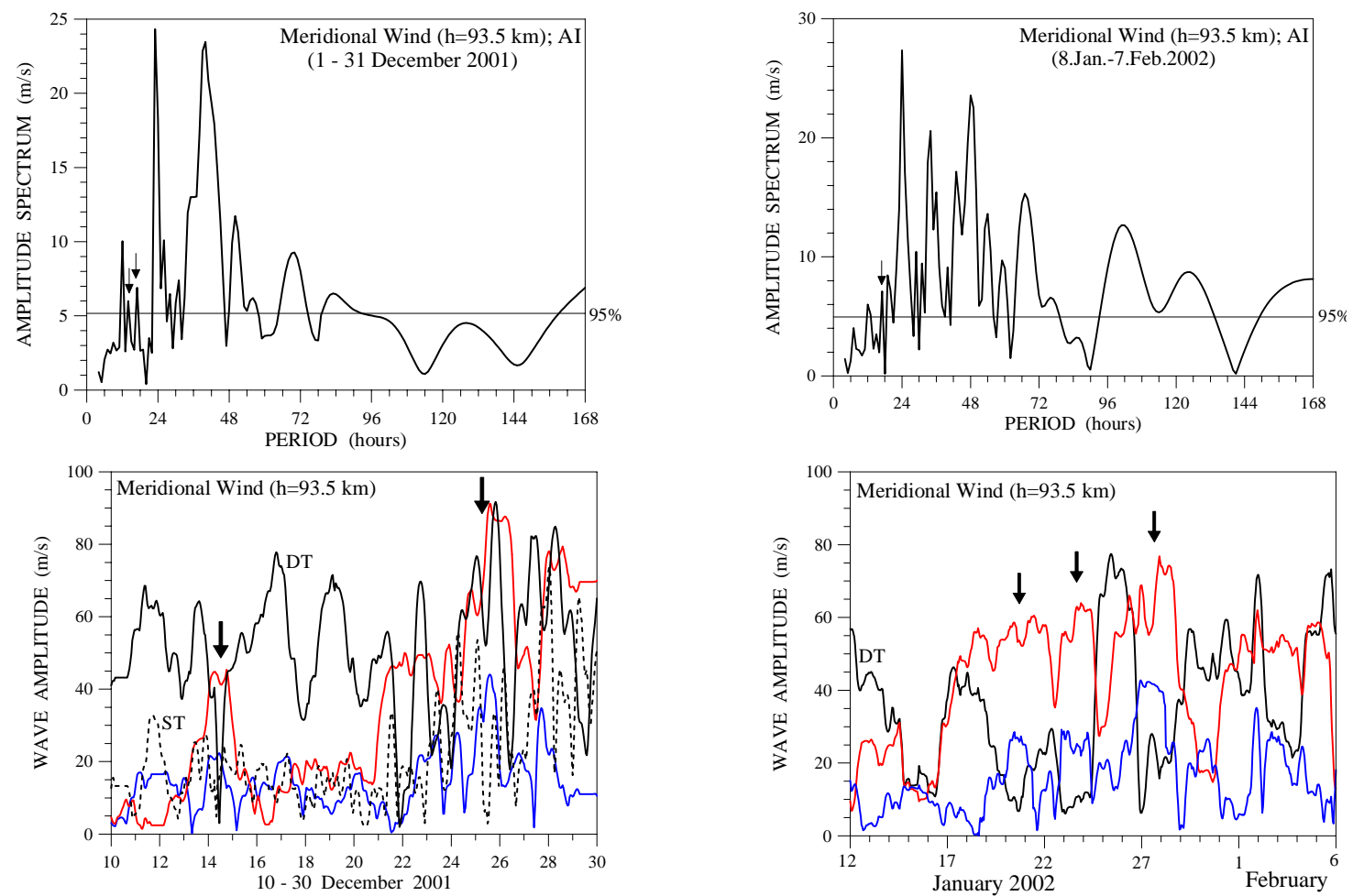

Fig. 14. Amplitude spectrum of the meridional wind observed from 1-31 December 2001 for altitude $93.5 \mathrm{~km}$. Marked by arrows peaks have periods respectively 14.5 and $17 \mathrm{~h}$ (upper left plot). Variability of the amplitudes of the diurnal (black solid line) and semidiurnal (black dashed line) tides obtained by the best fit procedure and the amplitudes of the 40-h (red line) and 16-h (blue line) waves obtained by the complex demodulation method (bottom left plot). Amplitude spectrum of the meridional wind observed in 8 January-7 February 2002 for altitude $93.5 \mathrm{~km}$ (upper right plot). Variability of the amplitudes of diurnal tide (black solid line), 48- (red line) and 16-h (blue line) waves obtained by the best fit procedure (bottom right plot). 
often the enhanced 2-day wave activity is accompanied by weak diurnal tide and vice versa. Usually the 16-h oscillation is also apparent. The upper left plot of Fig. 14 shows the amplitude spectrum of the meridional wind observed in December for altitude $93.5 \mathrm{~km}$. The 40-h wave was the strongest 2-day wave observed in this interval. If there is a coupling between the 40-h wave, on the one hand, and the diurnal (DT) and semidiurnal (ST) tides on the other, the secondary waves should have periods, respectively, of 15 and $17 \mathrm{~h}$. Peaks with periods 14.5 and $17 \mathrm{~h}$ marked by arrows can be found in the spectrum. The bottom left plot shows the variability of the amplitudes of the diurnal (black solid line) and semidiurnal (black dashed line) tides obtained by the best fit procedure described in Sect. 2. There are also the amplitudes of the 40-h (red line) and 16-h (blue line) waves obtained by the complex demodulation method (we cannot separate 15- and 17 -h waves). The variability of the 16 -h wave is very similar to that of the 40-h wave and usually their amplification is accompanied by a rapid decrease in the tidal amplitudes (shown by thick arrows). The right plots of the figure show a similar example observed, however, in January/February. The amplitude spectrum of the meridional wind observed at height $93.5 \mathrm{~km}$ shows a strong $16-\mathrm{h}$ wave that is a secondary wave generated by the DT and the 48-h wave (in this case the ST is very weak with amplitude even smaller than that of the 16-h wave). The bottom plot shows the variability of the DT, 48- and 16-h waves. Again, a clear anti-correlation is evident between the variability of the DT and the variability of the 48- and 16-h waves. These results support the suggestion that the secondary wave (16-h wave) grows at the expense of the DT.

\section{Conclusion}

The first observations reported in this work provide additional information about the characteristics of the planetary waves (1.5-10 days) measured by meteor radar at a different geographical location. The overall characteristics of the waves observed above Ascension Island are found to be generally in accord with the observations in other equatorial locations. The zonal wind is dominated by the 3-7-day waves, while the meridional component by the quasi-2-day wave. Two wave events in the zonal wind are studied in detail: 3-4day wave observed at the end of October/November and the 3-6-day wave in January/February. The moderate 3- and 3.2day waves are interpreted as an ultra-fast Kelvin wave, while for the strong 4-day wave we are not able to make a firm decision. It resembles the ultra-fast Kelvin wave with respect to its very large and increasing height amplitude (the amplitude larger than $30 \mathrm{~m} / \mathrm{s}$ is hardly typical for the normal modes) and short vertical wavelength (usually the normal mode planetary waves have a greater than $40 \mathrm{~km}$ vertical wavelength). But such Kelvin waves have not been found in the equatorial stratosphere (A. Pogoreltsev, private communication). The 6-day wave is interpreted as a Doppler-shifted 5-day normal mode due to its very large vertical wavelength $(79 \mathrm{~km})$. The quasi-2-day wave seems to be present almost continuously in the meridional wind, but the strongest bursts are observed mainly in December and January. The observed period range is large, from 34 to $68 \mathrm{~h}$, with some clustering around $43-44$ and $50 \mathrm{~h}$. The estimated vertical wavelengths indicate shorter lengths during the equinoxes, in the range of $25-30 \mathrm{~km}$, and longer ones, $\sim 40-50 \mathrm{~km}$, in January/February, when the 48 $\mathrm{h}$ wave is the strongest wave. To clarify the origin of the quasi-2-day wave we need simultaneous observations at several equatorial sites accompanied by numerical modelling using realistic conditions.

Acknowledgements. Topical Editor Ulf-Peter Hoppe thanks a referee for her/his help in evaluation his paper.

\section{References}

Andrews, D. G., Holton, J. R. and Leovy, C. B.: Middle Atmosphere Dynamics, Academic Press, New York, 1987.

Bloomfield, P.: Fourier Analysis of Time Series: An Introduction, John Wiley, New York, 1976.

Burks, D. and Leovy, C. B.: Planetary waves near the mesospheric easterly jet, Geophys. Res. Lett., 13, 193-196, 1986.

Coy, L.: A possible 2-day wave oscillation near the tropical stratopause, J. Atmos. Sci., 36, 1615-1618, 1979.

Craig, R. L., Vincent, R. A., Fraser, R. I., and Muller, H. G.: The quasi-2-day wave in the Southern Hemisphere mesosphere, Nature, 289, 319-320, 1980.

Dunkerton, T. J.: On the role of the Kelvin wave in the westerly phase of the semiannual zonal wind oscillation, J. Atmos. Sci., 36, 32-41, 1979.

Dunkerton, T. J.: Theory of mesopause semiannual oscillation, J. Atmos, Sci., 39, 2681-2690, 1982.

Dunkerton, T. J.: The role of gravity waves in the quasi-biennial oscillation, J. Geophys. Res., 102, 26 053-26 076, 1997.

Ebdon, R. A.: Notes on the wind flow at $50 \mathrm{mb}$ in tropical and subtropical regions in January 1957 and January 1958, Q. J. R. Meteorol. Soc., 86, 540-543, 1960.

Forbes, J. M.: Wave coupling between the lower and upper atmosphere: case study of an ultra-fast Kelvin wave, J. Atmos. Sol.Terr. Phys., 62, 1603-1621, 2000.

Garcia, R. R., Dunkerton, T. J., Lieberman, R. S., and Vincent, R. A.: Climatology of the semiannual oscillation of the tropical middle atmosphere, J. Geophys. Res., 102, 26 019-26 032, 1997.

Gurubaran, S., Sridharan, S., Ramkumar, T. K., and Rajaram, R. The mesospheric quasi-2-day wave over Tirunelveli $\left(8.7^{\circ} \mathrm{N}\right), \mathrm{J}$ Atmos. Sol.-Terr. Phys., 63, 975-985, 2001.

Hagan, M. E., Forbes, J. M., and Vial, F. : Numerical investigation of the propagation of the quasi- 2-day wave into the lower thermosphere, J. Geophys. Res., 98, 23 193-23 205, 1993.

Hamilton, K. P.: Rocketsonde observations of the mesospheric semiannual oscillations at Kwajalein, Atmos-Oceans., 20, 281286, 1982.

Harris, T. J. and Vincent, R. A.: The quasi-2-day wave observed in the equatorial middle atmosphere, J. Geophys. Res., 98, $10481-$ $10490,1993$.

Hirota, I.: Equatorial waves in the upper stratosphere and mesosphere in relation to the semiannual oscillation of the zonal wind, J. Atmos. Sci., 35, 714-722, 1978. 
Hitchman, M. H. and Leovy, C. B.: Estimation of the Kelvin wave contibution to the semiannual oscillation, J. Atmos. Sci., 45, 1462-1475, 1988.

Holton, J. R.: Introduction to Dynamic Meteorology, 3rd Ed., Academic Press, 1992.

Isoda, F., Tsuda, T., Nakamura, T., Murayama, Y., Igarashi, K., Vincent, R. A., Reid, I. M., Nurayanto, A., and Manurung, S. L.: Long-period wind oscillations in the mesosphere and lower thermosphere at Yamagawa $\left(32^{\circ} \mathrm{N}, 131^{\circ} \mathrm{E}\right)$, Pontianak $\left(0^{\circ} \mathrm{N}\right.$, $\left.109^{\circ} \mathrm{E}\right)$ and Christmas Island $\left(2^{\circ} \mathrm{N}, 157^{\circ} \mathrm{W}\right)$, J. Atmos. Sol.Terr. Phys., 64, 1055-1067, 2002.

Kopecky, M. and Kuklin, G.: About 11-year variation of the mean life duration of a group sun spots, Issled. Geomagn. Aeronom. Foz. Solntsa, 2, 167, 1971.

Kovalam, S., Vincent, R. A., Reid, I. M., Tsuda, T., Ohnishi, K., Nuryanto, A., and Wiryosumarto, H.: Longitudinal variations in planetary wave activity in the equatorial mesosphere, Earth Planets Space, 51, 665-674, 1999.

Lieberman, R. S. and Riggin, V.: High resolution Doppler imager observations of Kelvin waves in the equatorial mesosphere and lower thermosphere, J. Geophys, Res., 102, 26 117-26 130, 1997.

Lieberman, R. S.: Eliassen-Palm Fluxes of the 2-day wave, J. Atmos. Sci., 56, 2846-2861, 1999.

Lindzen, R. S. and Holton, J. R.: A theory of the quasi-biennial oscillation, J. Atmos. Sci., 25, 1095-1107, 1968.

Mitchell, N. J., Pancheva, D., Middleton, H., and Hagan, M.: Mean winds and tides in the Arctic mesosphere/lower thermosphere region and comparison with the GSWM, J. Geophys. Research., 107, A1, 2002.

Meek, C. E., Manson, A. H., Franke, S. J., Singer, W., Hoffmann, P., Clark, R. R., Tsuda, T., Nakamura, T., Hagan, M., Fritts, D. C., Isler, J., and Portnyagin, Y.: Global Study of northern hemisphere quasi-2-day wave events in recent summers near $90 \mathrm{~km}$ altitude, J. Atmos. Terr. Phys., 58, 1401-1411, 1996.

Muller, H. G.: Long-period meteor wind oscillations, Philos. Trans., Roy. Soc. London, 271, 585-598, 1972.

Muller, H. G. and Nelson, L.: A travelling quasi-2-day wave in the meteor region, J. Atmos. Terr. Phys., 40, 761-766, 1978.

Palo, S. E. and Avery, S. K.: Observations of the meridional quasitwo-day wave in the mesosphere and lower thermosphere at Christmas Island. The Upper Mesosphere and Lower Thermosphere: A Review of Experiment and Theory, Geophys. Monogr. Series, No 87, Amer. Geophys. Union, 101-110, 1995.

Pancheva, D. and Mukhtarov, P. : Wavelet analysis on transient behaviour of tidal amplitude fluctuations observed by meteor radar in the lower thermosphere over Bulgaria, Ann. Geophysicae., 18, 316-331, 2000.

Pfister, L.: Baroclinic instability of easterly jets with applications to the summer mesosphere, J. Atmos. Sci., 42, 313-330, 1985.

Plumb, R. A.: Baroclinic instability of the summer mesosphere: a mechanism for the quasi-two-day wave? J. Atmos. Sci., 40, 262 270, 1983

Plumb, R. A., Vincent, R A., and Craig, R. L.: The quasi-2-day wave event of January 1984 and its impact on the mean mesospheric circulation, J. Atmos. Sci., 44, 3030-3036, 1987.

Pogoreltsev, A. I., Fedulina, I. N., Mitchell, N. J., Muller, H. G., Luo, Y., Mekk, C. E., and Manson, A. H.: Global free oscillations of the atmosphere and secondary planetary waves in the
MLT region during August/September 1993 time conditions, J. Geophys. Res., doi: 10.1029/2001JD001535, 2002.

Raghava Reddi, C., Geetha, A., and Lekshmi, K. R.: Quasi-2-day wave in the middle atmosphere over Trivandrum, Ann. Geophys. 6, 231-238, 1988.

Reed, R. J.: Some features of the annual temperature regime in the tropical stratosphere, Mon. Wea. Rev., 90, 211-215, 1962.

Riggin, D., Fritts, D. C., Tsuda, T., Nakamura, T., and Vincent, R. A.: Radar observations of a 3- day Kelvin wave in the equatorial mesosphere, J. Geophys, Res., 102, 26 141-26 157, 1997.

Rodgers, C. D. and Prata, A. J.: Evidence for a travelling 2-day wave in the middle atmosphere, J. Geophys. Res., 86, 96619664, 1981.

Salby, M. L. and Roper, R.: Long-period oscillations in the meteor region, J. Atmos. Sci., 37, 237-244, 1980.

Salby, M. L.: The 2-day wave in the middle atmosphere: Observation and theory, J. Geophys. Res., 86, 9654-9660, 1981.

Salby, M. L., Hartmann, D. L., Bailey, P. L., and Gille, J. C.: Evidence for equatorial Kelvin modes in Nimbus-7 LIMS, J. Atmos. Sci., 41, 220-235, 1984.

Smith, A.: Observation of low frequency Kelvin waves in the mesosphere, Earth Planets Space, 51, 649-656, 1999.

Sridharan, S., Gurubaran, S., and Rajaram, R.: Radar observations of the 3.5-day ultra-fast Kelvin wave in the low-latitude mesosphere region, J. Atmos. Sol-Terr. Phys., 64, 1241-1250, 2002.

Thayaparan, T., Hocking, W. K., and MacDougall, J.: Amplitude, phase and period variations of the quasi-2-day wave in the mesosphere and lower thermosphere over London, Canada $\left(43^{\circ} \mathrm{N}\right.$, $81^{\circ} \mathrm{W}$ ), during 1993 and 1994. J. Geophys. Res., 102, 9461$9478,1997 \mathrm{a}$.

Thayaparan, T., Hocking, W. K., MacDougall, J., Manson, A. H., and Meek, C. E.: Simultaneous observations of the 2-day wave at London $\left(43^{\circ} \mathrm{N}, 81^{\circ} \mathrm{W}\right)$ and Saskatoon $\left(52^{\circ} \mathrm{N}, 107^{\circ} \mathrm{W}\right)$ near $91 \mathrm{~km}$ altitude during the two years of 1993 and 1994. Ann. Geophys., 15, 1324-1339, 1997b.

Torrence, C. and Compo, G.: A practical guide to wavelet analysis, Bull. Amer. Meteor. Soc., 79, 61-78, 1998.

Tsuda, T., Kato, S., and Vincent, R. A.: Long period oscillations observed by the Kyoto meteor radar and comparison of the quasi2-day wave with Adelaide MF radar observations, J. Atmos. Terr. Phys., 50, 225-230, 1988.

Vincent, R. A.: Low frequency dynamics of the equatorial mesosphere, in: Coupling Processes in the Lower and Middle Atmosphere, edited by Trane, E. V. et al., 125-136, Kluwer Academic Publisher, Netherlands, 1993.

Wallace, J. M. and Kousky, V.: Observational evidence of Kelvin waves in the tropical stratosphere, J. Atmos. Sci., 25, 900-907, 1968.

Ward, W. E., Yang, D. Y., Solheim, B. H., and Shepherd, G. G.: Observations of the 2-day wave in WINDII data during January 1993, Geophys. Res. Lett., 23, 2923-2926, 1996.

Wu, D. L., Hays, P. B., Skinner, W. R., Marshall, A. R., Burrage, M. D., Lieberman, R. S., and Ortland, D. A.: Observations of the quasi-2-day wave from the high resolution Doppler imager, Geophys. Res. Lett., 20, 2853-2856, 1993.

Yoshida, S., Tsuda, T., Shimuzu, A., and Nakamura, T.: Seasonal variations of 3.0-3.8-day ultra fast Kelvin waves observed with a meteor radar and radiosonde in Indonesia, Earth Planets Space, 51, 675-684, 1999. 